\title{
Non-canonical, potassium-driven cerebrospinal fluid clearance
}

2 Huixin $\mathrm{Xu}^{1, \neq}$, Ryann M Fame ${ }^{1, \ddagger}$, Cameron Sadegh ${ }^{1,2}$, Jason Sutin ${ }^{3}$, Christopher Naranjo ${ }^{4}$, Della $3 \mathrm{Syau}^{4}$, Jin Cui ${ }^{1}$, Frederick B Shipley ${ }^{1,5}$, Amanda Vernon ${ }^{6}$, Fan Gao ${ }^{6,}$, Yong Zhang ${ }^{7}$, Michael J.

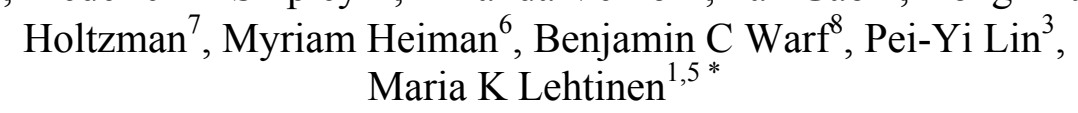

$7 \quad{ }^{1}$ Department of Pathology, Boston Children's Hospital, Boston, MA 02115, USA

$8{ }^{2}$ Department of Neurosurgery, Massachusetts General Hospital and Harvard Medical School, 9 Boston, MA 02114, USA

$10{ }^{3}$ Fetal-Neonatal Neuroimaging and Developmental Science Center, Division of Newborn 11 Medicine, Boston Children's Hospital, Harvard Medical School, 300 Longwood Avenue, Boston, 12 MA 02115, USA

13 ${ }^{4}$ Summer Honors Undergraduate Research Program, Division of Medical Sciences, Harvard 14 Medical School, Boston, MA 02115, USA

$15 \quad{ }^{5}$ Graduate Program in Biophysics, Harvard University, Cambridge, MA 02138, USA

$16{ }^{6}$ Broad Institute of MIT and Harvard, Cambridge, MA 02142; Picower Institute for Learning and 17 Memory, Cambridge, MA 02139; Department of Brain and Cognitive Sciences, Massachusetts 18 Institute of Technology, Cambridge, MA 02139, USA

$19{ }^{7}$ Pulmonary and Critical Care Medicine, Department of Medicine, Washington University, St. 20 Louis, MO 63110, USA

$21 \quad{ }^{8}$ Department of Neurosurgery, Boston Children's Hospital, Boston, MA 02115, USA

$22{ }^{\sharp}$ These authors contributed equally.

23 Current address: Bioinformatics Resource Center in the Beckman Institute at Caltech, Pasadena, 24 CA 91125, USA

$25 *$ Correspondence should be addressed to: maria.lehtinen@childrens.harvard.edu 
$\mathrm{Xu}$ and Fame, et al. 2

\section{ABSTRACT}

28 Cerebrospinal fluid (CSF) provides vital support for the brain. Abnormal CSF

29 accumulation is deleterious for perinatal neurodevelopment, but how CSF leaves the brain during

30 this critical period is unknown. We found in mice a postnatal neurodevelopmental transition

31 phase featuring precipitous $\mathrm{CSF}^{+}$clearance, accompanied by water, through the choroid plexus

32 (ChP). The period corresponds to a human fetal stage when canonical CSF clearance pathways

33 have yet to form and congenital hydrocephalus begins to manifest. Unbiased ChP metabolic and

34 ribosomal profiling highlighted this transition phase with increased ATP yield and activated

35 energy-dependent $\mathrm{K}^{+}$transporters, in particular the $\mathrm{Na}^{+}-\mathrm{K}^{+}-\mathrm{Cl}^{-}$and water cotransporter $\mathrm{NKCC} 1$.

36 ChP-targeted NKCC1 overexpression enhanced $\mathrm{K}^{+}$-driven CSF clearance and enabled more

37 permissive cerebral hydrodynamics. Moreover, ventriculomegaly in an obstructive

38 hydrocephalus model was improved by ChP-targeted NKCC1 overexpression. Collectively, we

39 identified $\mathrm{K}^{+}$-driven $\mathrm{CSF}$ clearance through $\mathrm{ChP}$ during a transient but critical

40 neurodevelopmental phase, with translational value for pathologic conditions.

42 Keywords: cerebrospinal fluid; clearance; potassium; choroid plexus; development; NKCC1;

43 hydrocephalus 
$\mathrm{Xu}$ and Fame, et al. 3

\section{INTRODUCTION}

A balance between cerebrospinal fluid (CSF) production and clearance (influx/efflux) is essential for normal brain function and development (Fame and Lehtinen, 2020). Disrupted CSF volume homeostasis with excessive CSF accumulation is implicated in many pediatric brain disorders, in particular congenital hydrocephalus (Kahle et al., 2016), where patients suffer from a potentially life-threatening accumulation of CSF and frequently develop neurological deficits

51 that last through childhood and into adult life (Vinchon et al., 2012). Schizophrenia patients can

52 have enlarged lateral ventricles by their first episode of psychosis (Steen et al., 2006), and in

53 some cases as early as infancy (Gilmore et al., 2010), suggesting a role for CSF clearance

54 abnormalities in this and possibly other neurodevelopmental disorders. As another example,

55 autism spectrum disorders are associated with altered CSF distribution patterns and enlarged

56 CSF space surrounding the brain (Shen et al., 2017). A better understanding of developing CSF

57 dynamics may help explain why early phases of brain development (e.g. from third trimester to 6

58 months after birth in human) represent a period of high vulnerability to certain congenial

59 disorders (Volpe, 2008, Gilmore et al., 2010, Shen et al., 2017).

Critically, how CSF is cleared during this perinatal period remains a mystery. Progress in

61 CSF dynamics research has identified several CSF clearance routes including arachnoid 62 granulations, perineural and paravascular pathways, and meningeal lymphatics (Antila et al.,

63 2017, Munk et al., 2019, Fame and Lehtinen, 2020). However, these systems only fully appear at

64 later stages of life (up to 2 years in human and several weeks postnatal in mice) (Antila et al., 65 2017, Munk et al., 2019), and therefore are not available to contribute to CSF dynamics during 66 these critical early phases. Identifying and manipulating the early endogenous CSF clearance 67 mechanisms could provide one powerful approach for tackling neurodevelopmental disorders 

involving CSF dysregulation, and may also be applied to fluid disorders affecting adults.

To identify how early CSF is cleared, we investigated tissues with the ability to modulate CSF at this stage. The choroid plexus $(\mathrm{ChP})$ is an intraventricular epithelial structure that forms the majority of the blood-CSF barrier and develops prenatally. It contains diverse ion and fluid transporters along its vast surface area capable of bidirectional transport (Damkier et al., 2013). Although the prevailing model posits that the ChP provides net unidirectional, luminal secretion

74 of ions and water to form CSF, insufficient corroborating data have been collected under

75 physiological experimental conditions. Furthermore, historical clinical observations suggest 76 some absorptive functions of the ChP (Milhorat et al., 1970) which is supported by animal 77 studies (Oreskovic et al., 2017). Finally, broad transcriptional changes of the machinery 78 regulating fluid/ion transport support the concept of temporally dynamic and possibly contextdependent ChP functions in determining net directionality of CSF transport (Liddelow et al., 2013, Delpire and Gagnon, 2019).

82 of transporters, the energetic systems and ionic gradients that govern their activity, and their

83 physiological effects across the timespan of early postnatal development in mice. Taken together

84 our data support a novel role and mechanism for CSF clearance by the $\mathrm{Na}^{+}-\mathrm{K}^{+}-\mathrm{Cl}^{-}$and water co-

85 transporter, $\mathrm{NKCC} 1$, in the apical membrane of the $\mathrm{ChP}$ during a specific developmental period.

86 These results have implications for the pathophysiology of congenital disorders accompanied by

87 dysregulated CSF and could inform strategies for treatment of neonatal hydrocephalus and 88 perhaps other disorders. 
$\mathrm{Xu}$ and Fame, et al. 5 111 (Keep and Jones, 1990, Damkier et al., 2013). Similar to water and ion transport by other 112 epithelial structures such as kidney proximal and distal tubes (Bhargava and Schnellmann, 2017),

\section{RESULTS}

\section{$\mathrm{CSF}^{+}$declines precipitously during a specific perinatal period}

We discovered a unique and transient phase of neurodevelopment when $\operatorname{CSF}\left[\mathrm{K}^{+}\right]$ decreased rapidly. We used inductively coupled plasma optical emission spectrometry (ICP-OES) and ion chromatography (IC) to measure levels of key ions likely to govern CSF flux including $\mathrm{Na}^{+}, \mathrm{K}^{+}$, and $\mathrm{Cl}^{-}$at several developmental timepoints. $\mathrm{CSF}\left[\mathrm{K}^{+}\right]$was remarkably high at birth $(9.6 \pm 3.5 \mathrm{mM}$ ), decreased rapidly to $4.4 \pm 0.9 \mathrm{mM}$ by P7 (Fig. 1A), and later achieved adult levels of $3.1 \pm 0.6 \mathrm{mM}$ (Fig. 1A) while $\left[\mathrm{Na}^{+}\right]$and $\left[\mathrm{Cl}^{-}\right]$were minimally changed (Fig. 1B). The reduction in $\mathrm{CSF} \mathrm{K}^{+}$was consistent with previous reports in other species (Saunders et al., 2018) and correlated with parallel changes in serum $\left[\mathrm{K}^{+}\right]$such that the ratio between blood and CSF $\left[\mathrm{K}^{+}\right]$remained stable (Fig. 1C).

Notably, $\mathrm{K}^{+}$transport has been associated with water co-transport by several $\mathrm{K}^{+}$ transporters in various tissues and cell types (Zeuthen, 1994, Hamann et al., 2010, Zeuthen and Macaulay, 2012), suggesting that $\mathrm{CSF}\left[\mathrm{K}^{+}\right]$changes could drive water movement in the brain as well. Therefore, we sought to identify mechanisms underlying this fast clearance of CSF $\mathrm{K}^{+}$, which may shed light on CSF outflow during this time.

\section{ChP metabolism increases during the early postnatal transition phase}

We found that the transitional period of rapid $\mathrm{CSF} \mathrm{K}^{+}$clearance coincided with high $\mathrm{ChP}$ metabolism. We reasoned that $\mathrm{K}^{+}$clearance during this period could be ChP-mediated because the $\mathrm{ChP}$ expresses high levels of $\mathrm{K}^{+}$co-transporters on its large CSF-contacting surface area 
$113 \mathrm{~K}^{+}$clearance from CSF by the ChP would be energy-dependent and therefore be accompanied by

114 upregulation of ATP production and mitochondrial activity. Therefore, we evaluated the

115 metabolic status and ATP production capacity of the ChP epithelium before, during, and after the

116 time period of $\mathrm{CSF}\left[\mathrm{K}^{+}\right]$reduction. We found that both mitochondria number and size increased

117 from E16.5 to 2mo (Fig. 1D-G), while cellular glycogen load gradually decreased

118 (Supplementary Fig. 1). Both observations are consistent with reports from ChP in other

119 mammalian species (Netsky and Shuangshoti, 1975, Keep and Jones, 1990) and suggest

120 functional changes in $\mathrm{ChP}$ oxidative metabolism. To assess this we monitored oxygen

121 consumption to calculate basal metabolism and ATP production at embryonic day 16.5 (E16.5),

122 postnatal day 0 (P0), P7, and adult (2 months old (2mo)) ChP explants using Agilent Seahorse

123 XFe technology (Fig. 1H, Supplementary Fig. 2). We found that E16.5 ChP had the lowest

124 basal respiration of all tested ages (Fig. 1I, Supplementary Fig. 2). Adult had a higher capacity

125 for overall ATP production than E16.5 $\mathrm{ChP}$, but surprisingly, P0-P7 ChP were the most

126 metabolically active as per ATP production (Fig. 1I, J). In addition, mitochondrial subcellular

127 distribution in $\mathrm{ChP}$ epithelium was biased toward the apical surface as postnatal development

128 proceeded, with E16.5 mitochondria heavily distributed along the basal side of epithelial cells,

129 P0 mitochondria intermediately localized, and P7 and 2mo mitochondria having more apical

130 distribution (Fig. 1K-M, Supplementary Fig. 3). Mitochondrial subcellular localization

131 responds to regional energy demand in other cellular processes such as migration of mouse

132 embryonic fibroblasts and during axonal outgrowth (Schuler et al., 2017, Smith and Gallo, 2018).

133 Together with the increase in ATP production postnatally, the shift in ChP epithelial

134 mitochondria distribution over postnatal development suggests increasing ATP supply to meet

135 high demand at the apical ChP surface during the early postnatal phase, concurrent with the rapid 
136 clearance of $\mathrm{CSF} \mathrm{K}^{+}$. This concurrence prompted us to investigate energy-dependent

137 mechanisms whereby $\mathrm{ChP}$ epithelial cells might contribute to $\mathrm{K}^{+}$clearance.

\section{The ChP increases production of CSF-facing ion and water transporters postnatally}

Consistent with rapid $\mathrm{CSF} \mathrm{K}^{+}$clearance and high ChP metabolism, we found that expression of the energy-dependent cation transport pathway components were upregulated in ChP postnatally. To unbiasedly identify candidates controlling postnatal CSF clearance through the $\mathrm{ChP}$, we conducted ribosomal profiling to investigate transcripts that are prioritized for translation in embryonic (E16.5) and adult (2 mo) ChP, using Translating Ribosomal Affinity Purification (TRAP; Heiman et al., 2008). ChP epithelial cells were targeted by crossing FoxJ1:cre mice (Zhang et al., 2007) with TRAP (EGFP:L10a) mice (Heiman et al., 2008) (Fig. 2A, Supplementary Fig. 4A, B), and mRNA associated with the L10a ribosomal subunit were purified for sequencing.

TRAP analyses revealed 1967 differentially translated transcripts (adjusted $p<0.05$ ) between E16.5 and 2mo adult ChP: 1119 enriched at E16.5 and 847 enriched at 2mo (Fig. 2B). Gene set and pathway analyses revealed developmentally regulated ChP programs. Adult (2mo) ChP had enriched functional gene sets associated with active transmembrane membrane transport and mitochondria, which is consistent with our abovementioned findings on metabolism changes (Fig. 2C). Specifically, cation transport was enriched, supporting the hypothesis of ChP mediating CSF $\mathrm{K}^{+}$transport postnatally (Fig. 2C, D). Enriched pathways in the 2 mo adult included secretion associated pathways named for other, better studied secretory processes, including salivary and pancreatic secretion, all of which have a special emphasis on water and ion transmembrane transport (Supplementary Fig. 4C (red), D). Consistent with a rise in fluid and ion modulating machinery, there was a striking enrichment of more 
$\mathrm{Xu}$ and Fame, et al. 8

transmembrane and signal peptide-containing transcripts in adult ChP (Supplementary Fig. 4E,

160 F). These results indicate that the ChP specifically gained fluid and ion modulatory functions

161 postnatally.

162

NKCC1 is poised to mediate perinatal $\mathrm{ChP} \mathrm{CSF} \mathrm{K}^{+}$and water clearance

Among all fluid and ion modulating candidates with increasing postnatal expression

(Supplementary Fig. 4G, H), we identified NKCC1 (Slc12a2) as the candidate most likely to mediate CSF clearance. NKCC1 is functionally related to $\mathrm{Na}^{+} / \mathrm{K}^{+}$-ATPase (Atplal and Atplbl), as the latter actively maintains the $\mathrm{Na}^{+} / \mathrm{K}^{+}$gradient that powers $\mathrm{NKCC} 1$. Both $\mathrm{Na}^{+} / \mathrm{K}^{+}$-ATPase and $\mathrm{NKCC} 1$ are capable of CSF $\mathrm{K}^{+}$clearance, but NKCC1 was of particular interest because (1) it is a co-transporter of $\mathrm{K}^{+}$and water (Zeuthen and Macaulay, 2012, Steffensen et al., 2018); and (2) the activity of NKCC1 can be further modified by phosphorylation (Darman and Forbush,

171 2002), lending additional control to its fluid/ion modulatory capacity. In addition, NKCC1 is

172 particularly enriched in the $\mathrm{ChP}$ and does not impact broad functionality like the $\mathrm{Na}^{+} / \mathrm{K}^{+}$-ATPase

173 does, both of which are ideal features for a functional therapeutic intervention target. We refined 174 our temporal expression analyses of NKCC1, ATP1a1, ATP1b1, and Klotho (Kl), which 175 contributes to the membrane localization of the $\mathrm{Na}^{+} / \mathrm{K}^{+}$-ATPase (Razzaque, 2008, Sopjani et al.,

176 2011) (Fig. 2E), by sampling weekly from P0 to P28 and then at $2 \mathrm{mo}$ and confirmed increased 177 expression of transcript and protein for each component across developmental time (Fig. 2F, G,

178 Supplementary Fig. 5). The observed changes in NKCC1 total protein were corroborated by an 179 independent approach where the rate of $\mathrm{ChP}$ epithelial cell swelling under high $\left[\mathrm{K}^{+}\right]$challenge 180 (Steffensen et al., 2018) reflected the abundance of NKCC1 protein (Fig. 2H-J, Supplementary $181 \quad$ Fig. 6). 
In addition, we found particularly high levels of phosphorylated, therefore activated

183 (Darman and Forbush, 2002), NKCC1 (pNKCC1) in the ChP of P0-P7 pups, with P7 having

184 peak pNKCC1 levels among all postnatal ages, indicative of increased NKCC1 activity during

185 the first postnatal week (Fig. 2G). Similar to the timeline of ChP ATP production (Fig. 1J), the

186 timeframe of high ChP pNKCC1 was concurrent with the fast CSF $\left[\mathrm{K}^{+}\right]$decrease during the first

187 postnatal week (Fig. 1A), suggesting a functional correlation and further confirming the 188 significance of the early postnatal transitional period. Taken together, we identified ChP NKCC1 189 as the top candidate for mediating postnatal CSF $\mathrm{K}^{+}$and water clearance.

NKCC1 temporal regulation requires epigenetic control that is implicated in congenital

We found that the temporal profile of $\mathrm{NKCC} 1$ expression was tightly regulated at the

194 epigenetic level by modulators implicated in some forms of congenital hydrocephalus. The

195 NuRD complex governs differentiation and maturation of diverse cells and tissues (Goodman

196 and Bonni, 2019). Our previously published RNA sequencing studies (Lun et al., 2015)

197 identified NuRD components, including the ATPase CHD family members (Chd4 being the most

198 highly expressed), the histone deacetylases HDAC1/2, and methyl CpG-binding domain protein

199 MBD3 in the ChP (Fig. 3A). De novo loss-of-function CHD4 mutations are implicated in some

200 groups of children with congenital hydrocephalus and ventriculomegaly (Weiss et al., 2020). We

201 found that CHD4 localized to nuclei in mouse ChP epithelial cells beginning at P0 (Fig. 3B).

202 Immunoprecipitation of CHD4 identified HDAC1, HDAC2, and MBD3 by immunoblotting in

203 mouse ChP (Fig. 3C, technical control for Co-IP protocol is shown in Supplementary Fig. 7),

204 confirming the existence of the CHD4/NuRD complex in developing ChP. We then disrupted the 
complex by generating ChP-Chd4 deficient mice. Cre was expressed in Chd4 floxed mice (Chd4 fl/fl) (Williams et al., 2004) using an adeno-associated viral vector (AAV) with tropism for the ChP (AAV2/5) (Haddad et al., 2013), delivered by in utero intracerebroventricular (ICV) injection at E14.5. Chd4 transcript levels dropped to $<50 \%$ by P7 (Fig. 3D). While CHD4 protein levels only substantially decreased by P14 (Fig. 3E, G), we found that the developmental

210 increase of ChP NKCC1 expression was disrupted as soon as the CHD4 protein decreased and

211 lasted at least until P28 (Fig. 3F, G). Similar results were also observed in 4VChP (Fig. 3H, I).

212 The expression of other developmentally regulated, functionally relevant candidates (atpla1, 213 atplb1, and klotho) was not affected (data not shown). These data confirm that the NuRD/ChD4

214 complex is one of the required components tightly regulating $\mathrm{ChP}$ NKCC1 developmental 215 expression.

\section{ChP NKCC1 actively mediates CSF clearance during the early postnatal transition phase} ChP epithelial cells using AAV2/5. NKCC1 transport directionality follows combined $\mathrm{Na}^{+}, \mathrm{K}^{+}$,

$221 \mathrm{Cl}^{-}$gradients, which are close to being neutral in adult brains and likely to bias towards the CSF-

222 to-ChP direction during the early postnatal phase. NKCC1 protein level would be rate-limiting 223 during the early postnatal time when it is already highly phosphorylated, unlike in older mice 224 where pNKCC1 only represented a small portion of total NKCC1. The goal of this OE approach 225 was to accelerate endogenous $\mathrm{ChP} \mathrm{NKCC1} \mathrm{transport,} \mathrm{thereby} \mathrm{revealing} \mathrm{its} \mathrm{directionality} \mathrm{based}$ 226 on whether $\mathrm{CSF}\left[\mathrm{K}^{+}\right]$clearance was enhanced or delayed. AAV2/5-NKCC1, which expresses 227 NKCC1 fused to an HA tag (Somasekharan et al., 2013), or control GFP virus was delivered by 
in utero ICV at E14.5. Successful NKCC1 OE and increased pNKCC1 was confirmed in ChP at P0 (Fig. 4A-D). Appropriate localization to apical membranes of epithelial cells, transduction efficiency, and tissue specificity were also validated (Fig. 4E-I, Supplementary Fig. 8 A, B). Transcript levels of other $\mathrm{K}^{+}$transporters or channels did not change following AAV2/5-NKCC1 transduction (Supplementary Fig. 8C). Because CSF $\left[\mathrm{K}^{+}\right]$sharply decreased from P0 to P7 (Fig. 1A), we sampled CSF from $\mathrm{ChP} \mathrm{NKCC1} \mathrm{OE}$ and control mice at P1. We found that ChP NKCC1 OE reduced CSF $\left[\mathrm{K}^{+}\right]$more than controls, with their P1 CSF $\left[\mathrm{K}^{+}\right]$values closely approximating those normally observed at P7 (Fig. 4J), indicating accelerated $\mathrm{K}^{+}$clearance from CSF after enhanced ChP NKCC1 activity. CSF total protein levels were not affected (AAV2/5$\mathrm{GFP}=2.50 \pm 0.20 \mathrm{mg} / \mathrm{ml}$ vs. AAV2 $/ 5-\mathrm{NKCC} 1=2.71 \pm 0.46 \mathrm{mg} / \mathrm{ml} ; \mathrm{N}=6$ from two litters each; $p=0.34$, unpaired t-test). Overall, these findings support a model in which, under physiological conditions with high early postnatal CSF $\left[\mathrm{K}^{+}\right]$, ChP NKCC1 transports $\mathrm{K}^{+}$out of CSF. as reflected by smaller lateral ventricles. To avoid any tissue processing artifacts, we conducted

242 live T2-weighted magnetic resonance imaging (MRI) (Fig. 5A) to quantify lateral ventricle 243 volume. AAV-GFP mice were indistinguishable from naive wild-type mice at P14. In contrast,

244 NKCC1 OE mice had reduced lateral ventricle volumes (Fig. 5A, B), without decrease in overall

245 brain size (Fig. 5C), reflecting less circulating CSF. The difference in ventricle sizes from these same mice was sustained up to our final measurement at P50 (AAV-GFP: $3.12 \pm 0.59 \mathrm{~mm}^{3}$ vs. AAV-NKCC1: $\left.1.28 \pm 0.28 \mathrm{~mm}^{3},{ }^{*} p=0.0182\right)$. While the exact transport direction of NKCC1 in 248 adult $\mathrm{ChP}$ is still under debate (Delpire and Gagnon, 2019), the consistency in ventricular

249 volume from P14 into later life supports our working model that because a relatively small 250 proportion of ChP NKCC1 was phosphorylated in mice P14 and older (Fig. 2G), NKCC1 levels 

are not rate-limiting and thus $\mathrm{OE}$ would not as substantially impact ChP functions in older

252 animals. Collectively, our findings demonstrate that ChP NKCC1 mediated CSF clearance

253 during the first postnatal week. Augmenting this process impacted CSF volume homeostasis in

254 the long term. changed how the brain and cranial space adapted to CSF volume changes. Intracranial compliance $\left(\mathrm{C}_{\mathrm{i}}\right)$ and $\mathrm{CSF}$ resistance $\left(\mathrm{R}_{\mathrm{CSF}}\right)$ describe the ability of the entire intracranial space

258 (including brain, meninges, and outflow routes) to accommodate an increasing CSF volume that 259 would otherwise increase intracranial pressure (ICP). In humans, these parameters are measured 260 by a CSF constant rate infusion test (Aquilina et al., 2012, Eide, 2018, Lalou et al., 2018) and 261 can aid in diagnosis and evaluation of conditions like hydrocephalus, which has decreased $\mathrm{C}_{\mathrm{i}}$ 262 (Kahle et al., 2016). We developed a miniaturized version of this test to determine the $\mathrm{C}_{\mathrm{i}}$ and $263 \mathrm{R}_{\mathrm{CSF}}$ in mice. The constant rate infusion test artificially increases CSF volume by ICV infusion 264 of artificial CSF (aCSF), causing ICP to rise and plateau at a new level (Fig. 5D, E). The $\mathrm{C}_{\mathrm{i}}$ and $265 \mathrm{R}_{\mathrm{CSF}}$ are estimated from the ICP vs. time curve using Marmarou's model of CSF dynamics 266 (Czosnyka et al., 2012) (Supplementary Fig. 9A). Simply put, the $C_{i}$ is proportional to the rate 267 of ICP increase, and the $\mathrm{R}_{\mathrm{CSF}}$ is related to the level of the post-infusion ICP plateau (Fig. 5E). As 268 a quality control for the correct placement of infusion and measurement catheter, arterial and 269 respiratory pulsations were clearly visible in the ICP waveform and their amplitude increased 270 with volume load as expected (Supplementary Fig. 9B, C). Using this approach, we found that 271 ChP NKCC1 OE significantly increased $\mathrm{C}_{\mathrm{i}}$ at an age of 5-7 weeks (Fig. 5F, G), consistent with 272 the brain having greater capacity for CSF in ventricles "deflated" due to excessive CSF clearance. 273 Resting ICP and $\mathrm{R}_{\mathrm{CSF}}$ were unchanged (Fig. 5H, I). 
$\mathrm{Xu}$ and Fame, et al. 13

275 Enhanced ChP NKCC1 function mitigates ventriculomegaly in a model of obstructive 276 hydrocephalus

277 Our findings of enhanced CSF clearance after ChP NKCC1 OE indicate that ChP

278 NKCC1 can remove excess CSF. Therefore, we hypothesized that ChP NKCC1 OE expression

279 could mitigate ventriculomegaly in a model of postnatal obstructive hydrocephalus. We first

280 overexpressed $\mathrm{ChP} \mathrm{NKCC1}$ at E14.5 by in utero AAV2/5 ICV, then introduced obstructive

281 hydrocephalus by a single unilateral injecting of kaolin into the lateral ventricle at P4 (Shaolin et

282 al., 2015), and finally evaluated the lateral ventricle volumes by live T2 MRI at P14 (Fig. 6A).

283 While both NKCC1 OE and control mice had enlarged ventricles at P14, NKCC1 OE mice had

284 reduced ventriculomegaly compared to controls, with the average ventricle volume being less

285 than 1/3 of the controls (Fig. 6B-D; ventricles marked by blue arrows; kaolin deposits marked by

286 red arrows). Taken together, our findings demonstrate that early, ChP targeted NKCC1 OE has a

287 sustained and broad impact on specific volumetric and biophysical parameters of the intracranial

288 space with potential therapeutic applications to hydrocephalus. 
$\mathrm{Xu}$ and Fame, et al. 14

\section{DISCUSSION}

In this study we sought to understand how CSF is cleared from the brain before the development of canonical CSF outflow routes (e.g. arachnoid granulations and meningeal lymphatics) (Antila et al., 2017, Munk et al., 2019). The intervening time period is a critical, transient phase in brain development when failure of CSF clearance has debilitating consequences (Volpe, 2008). Our results suggest that this period is defined by rapid decrease in CSF $\mathrm{K}^{+}$. The ChP mediates the CSF $\mathrm{K}^{+}$clearance during this transition period, and thus forms a CSF outflow route through ion and water co-transport by NKCC1 (Fig. 7). This CSF clearance by the ChP contrasts the prevailing models that ChP constantly, unidirectionally secretes CSF. Taken together, we discovered an unconventional, precisely timed, function of the developing ChP that clears CSF prior to the formation of other canonical routes, and provides targets for fluid management intervention during a critical transition phase of brain development.

NKCC1 is a bidirectional transporter, recently discovered to be an important cotransporter of water in the adult ChP (Steffensen et al., 2018). Although clearly established as a key molecular mechanism of $\mathrm{CSF}$ regulation, $\mathrm{ChP} \mathrm{NKCC1}$ transport direction and its determinants in vivo have been actively debated due to the technical challenges of 1) specifically manipulating ChP NKCC1 without affecting NKCC1 in other CSF-contacting cells, instead of ICV application of chemicals such as NKCC1 inhibitor bumetanide; and 2) accurately determining intracellular ion levels of $\mathrm{ChP}$ epithelial cells, and therefore ion gradients, under physiological conditions, as summarized in Supplementary Table 1 and reviewed by Delpire and Gagnon (Delpire and Gagnon, 2019). Our in vivo "gain-of-function" approach effectively bypasses the abovementioned technical limitations. By overexpressing NKCC1 specifically in the ChP through AAV transduction to amplify its physiological functional impact, we could 
313 subsequently observe the resulting $\mathrm{CSF} \mathrm{K}^{+}$and fluid volume changes to reveal the transporter's

314 native directionality. Using this approach, we found that, in contrast to the common notion that

315 the ChP constantly produces CSF, NKCC1 in the ChP mediated CSF clearance when CSF [K $\left.{ }^{+}\right]$

316 is above adult values, especially during the first postnatal week in mice. This phase corresponds

317 to the third trimester to 6 months after birth in human, which represents a window of high

318 vulnerability to congenial fluid disorders (Volpe, 2008).

319 We next demonstrated that the ChP clearance of CSF can be targeted to temper abnormal

320 CSF accumulation. The ChP has been targeted for therapeutic manipulation in rodent models of

321 neurologic diseases ranging from Huntington's disease and lysosomal storage disorders, to

322 Alzheimer's disease, where transduction of exogenous gene products into ependymal or ChP

323 epithelial cells has improved cardinal symptoms of disease (Kaler, 1994, Hudry et al., 2013).

324 Encouragingly, we showed that enhancing ChP epithelial cell NKCC1 transport capacity

325 lessened the severity of ventriculomegaly in a model of obstructive hydrocephalus. Our data

326 demonstrate the possibility of tempering congenital hydrocephalus by augmenting endogenous

327 ChP NKCC1 activity to increase CSF absorption rates during early development when CSF $\left[\mathrm{K}^{+}\right]$

328 is high. In addition, because ChP CSF absorption via NKCC1 is driven by increased CSF [K ${ }^{+}$,

329 this mechanism may come into play in other pathogenic conditions where CSF $\left[\mathrm{K}^{+}\right]$is transiently

330 increased, such as after tissue injury or ventricular bleeding. Therefore, our findings emphasize

331 the $\mathrm{ChP}$ as a targetable, $\mathrm{K}^{+}$-sensitive and on-demand $\mathrm{CSF}$ drainage route in neurological

332 disorders where CSF homeostasis is disrupted.

333 Further, in light of recent findings reporting hydrocephalus and ventriculomegaly in

334 children with de novo loss-of-function CHD4 mutations (Weiss et al., 2020), we found that the

335 CHD4/NuRD complex is required for the developmental regulation of NKCC1 expression. This 
connection suggests a possible pathophysiological mechanism whereby lack of CHD4 activity might reduce NKCC1 levels during early development (equivalent to P0-P7 in mice), and lead to insufficient CSF clearance resulting in hydrocephalus. In our loxP-cre approach, most CHD4 protein knockdown and resulting stagnation of $\mathrm{NKCC1}$ expression occurred by $\mathrm{P} 14$, which is beyond the critical window of NKCC1 activity at P0-P7. As such, we did not model

341 developmental ventriculomegaly with this approach. Improved genetic tools for early CHD4

342 knockout and new animal models harboring the de novo patient mutations would be required to

343 fully unravel the regulatory connection between CHD4/NuRD complex and NKCC1. pathway rather than a source of CSF during this transitional developmental phase - where does the early CSF water content come from? One mechanism that could be acting at this stage is CSF

347 secretion by the developing brain tissue (e.g. progenitor cells that have a cell body at the 348 ventricular zone but extend their basal processes to the developing pia) which secretes CSF 349 immediately after neural tube closure (Gato et al., 2014). Future studies should elucidate whether 350 this mechanism extends into this transitional phase. Consistent with progenitor involvement in 351 CSF dynamics, recent identification of genes driving pediatric hydrocephalus shows affected 352 genes to be expressed predominantly by cortical progenitor cells lining the brain's ventricles 353 (Furey et al., 2018), and not the ChP, suggesting a non-choroidal source of CSF as an alternative 354 contributor to abnormal CSF production.

In addition to fluid regulation, the newly identified $\mathrm{ChP}$ clearance route provides a key 356 mechanism to regulate extracellular $\mathrm{K}^{+}$during the first postnatal week. The subunits of the major 357 system for moving $\mathrm{K}^{+}$against its individual concentration gradient, the $\mathrm{Na}^{+} / \mathrm{K}^{+}$-ATPase (i.e. 358 Atpla1 and Atp1b1), were not yet at their full expression levels during this period. The ChP 
NKCC1-mediated $\mathrm{K}^{+}$clearance mechanism might assist in establishing the $\mathrm{K}^{+}$gradient in a

360 timely manner, which is crucial for cellular physiology (Rasmussen et al., 2020). Notably, the

361 period of rapidly decreasing $\mathrm{CSF}\left[\mathrm{K}^{+}\right]$overlaps with the developmental phase when the

362 excitatory-to-inhibitory "GABA switch" occurs. In early cortical progenitor cells that reside in

363 the ventricular zone and are bathed by CSF, the classic inhibitory neurotransmitter GABA leads

364 to excitatory potentials and suppression of DNA synthesis (LoTurco et al., 1995). As newborn

365 cortical neurons differentiate and migrate away from the ventricular zone, GABA switches to

366 adopt the more classic role as an inhibitory neurotransmitter by lowering intracellular $\mathrm{Cl}^{-}(\mathrm{Owens}$

367 et al., 1999) which is achieved through coordinated activities of neuronal $\mathrm{K}^{+} / \mathrm{Cl}^{-}$co-transporters

368 KCC2 and NKCC1 (Pisella et al., 2019, Watanabe et al., 2019). Because ions, including $\mathrm{K}^{+}$, can

369 traffic from CSF into interstitial fluid (Cserr, 1965, Fencl et al., 1966), any interference with the

370 developmental timeline of $\mathrm{ChP}$ NKCC1 that resulted in delayed $\mathrm{CSF} \mathrm{K}^{+}$clearance could

371 potentially increase extracellular/interstitial fluid $\left[\mathrm{K}^{+}\right]$and affect neural physiology (Rasmussen

372 et al., 2020). Specifically, such a change in extracellular/interstitial fluid [ $\left.\mathrm{K}^{+}\right]$could

373 fundamentally impact neuronal $\mathrm{NKCC} 1$ and $\mathrm{KCC} 2$ transport equilibrium, potentially

374 contributing to a delayed GABA switch, a phenomenon reported in many models of

375 neurodevelopmental and psychiatric disorders including subtypes of autism spectrum disorder

376 (Amin et al., 2017), Rett syndrome (Banerjee et al., 2016), Fragile X syndrome (He et al., 2014),

377 schizophrenia (Hyde et al., 2011), and Down syndrome (Deidda et al., 2015). Furthermore,

378 extracellular $\left[\mathrm{K}^{+}\right]$and certain $\mathrm{K}^{+}$channels also regulate activities of microglia (Madry et al.,

379 2018), which are critical in synaptic pruning during postnatal neurodevelopment in mice

380 (Schafer et al., 2012). Thus, the ChP is poised to play important roles in proper CNS formation

381 by creating and maintaining desirable extracellular ionic homeostasis at different developmental 
382 stages, with subsequent effects on neuronal maturation, circuit formation, and 383 neuroinflammatory homeostasis.

384 Beyond key findings and implications during this critical transitional developmental stage, 385 our study introduced a murine ICP measurement device combined with constant CSF infusion.

386 This approach provides a much-needed advance in fluid research technology that can be broadly 387 applied to study essentially all CSF dynamic systems across the mouse lifespan. We adapted our 388 tool from clinical practice to provide a range of options for measuring global cerebral fluid states 389 that reflect the interaction between CSF and cranial tissues. In later life, CSF homeostasis is 390 maintained by collaborative efforts from multiple players in the brain, including the ChP, the 391 dural lymphatics (Antila et al., 2017), glymphatics (Munk et al., 2019), leptomeningeal 392 vasculature ( $\mathrm{Li}$ et al., 2020), and the ependyma (Spassky et al., 2005). While this approach 393 measures overall cranial fluid dynamics as one single unit, future applications could apply 394 mathematical models that have been proposed to isolate the contribution of distinct CSF outflow 395 routes using data acquired from human patients (Vinje et al., 2020). Such adaptability secures the 396 broadening relevance of our tool and inspires optimism for further improved resolution in 397 studying brain fluid dynamics. Availability of this new tool also allows future researchers to 398 obtain measurements in support of the growing comprehensive "systems" view of regulatory 399 mechanisms of CSF-brain interactions. In summary, our study presents a critical transient phase when the $\mathrm{ChP}$ acts as a non401 canonical route for CSF clearance prior to the maturation of other canonical clearance pathways. 402 ChP NKCC1 mediates CSF clearance in a $\mathrm{K}^{+}$-dependent manner. Targeting this absorption route 403 holds promise in improving fluid management for congenital hydrocephalus and other CSF 404 disorders. 
$\mathrm{Xu}$ and Fame, et al. 19

\section{ACKNOWLEDGEMENTS}

We thank members of the Lehtinen, Heiman, and Warf labs for helpful discussions; Nancy Chamberlin for critical reading of the manuscript; Katia Georgopoulos for sharing the Chd4 $\mathrm{fl} / \mathrm{fl}$ mouse line and associated genotyping methods; P. Ellen Grant for the ICP monitor. We thank the following facility and personnel: Maria Ericsson and HMS EM facility; Yaotang Wu and Michael Marcotrigiano and BCH Small Animal Imaging Laboratory; the MIT BioMicro Center (TRAP sequencing); BCH viral core and University of Pennsylvania Vector Core. Funding: NIH T32 HL110852 (RMF and JC); William Randolph Hearst Fund (JC); NSF Graduate Research Fellowship Program (FBS); OFD/BTREC/CTREC Faculty Development Fellowship Award (RMF); Simons Foundation Autism Research Awards (IDs 590293 and 645596 for CN and DS, respectively). NIH R01 AI130591 and R35 HL145242 (MJH); NIH R00 HD083512 (P-YL) and R01 HD096693 (P-YL \& BCW); BCH Pilot Grant, Pediatric Hydrocephalus Foundation, Hydrocephalus Association, Human Frontier Science Program (HFSP) research program grant \#RGP0063/2018, NIH R01 NS088566, the New York Stem Cell Foundation (MKL); and BCH IDDRC 1U54HD090255. M.K. Lehtinen is a New York Stem Cell Foundation - Robertson Investigator.

Author contributions: H.X., R.M.F., C.S. J.S., P.-Y. L., B.C.W., F.B.S., J.C., D.S., C.N., and M.K.L. designed and performed experiments; H.X., R.M.F., C.S., and J.S. analyzed the data; Y.Z. and M.J.H. provided material; A.V., F.G., and M.H. provided technological support; H.X., R.M.F., and M.K.L. wrote the manuscript. All co-authors edited the manuscript.

Declaration of interests: The authors declare that no competing interests exist. 
$\mathrm{Xu}$ and Fame, et al. 20

\section{METHODS}

429

430

431

432

433 mice were equally included in the study and were analyzed at postnatal day $0,7,14,21,28,5$ -

434 7weeks, and 2+ months. Animals were housed in a temperature-controlled room on a 12-hr

435 light/12-hr dark cycle and had free access to food and water. For studies involving mice younger

436 than postnatal day 10, all mice were allocated into groups based solely on the gestational age

437 without respect to sex (both males and females were included). For studies involving mice older

438 than 10 days, both male and female are included intentionally. 444 chromatography (IC) was used for the $\mathrm{Cl}^{-}$quantification. All tests were performed using $5-7 \mu \mathrm{L}$ 445 of CSF.

\section{CSF Collection and Metal Detection}

CSF was collected by from cisterna magna using a glass capillary, and collected CSF was centrifuged at $10,000 \mathrm{xg}$ for $10 \mathrm{~min}$ at $4^{\circ} \mathrm{C}$ to remove any tissue debris. Metal quantifications were performed by Galbraith Laboratories, Inc. (Knoxville, TN, USA). Inductively coupled plasma optical emission spectrometry (ICP-OES) was used for $\mathrm{K}$ and $\mathrm{Na}$ quantification, and ion

\section{$\underline{\text { TRAP }}$}

Mice aged 8 weeks or E16.5 from the Foxj1:Cre x EGFP-L10a Bacterial Artificial Chromosome (BAC) transgenic lines $(\mathrm{N}=3$, each $\mathrm{N}$ included LVChP pooled from 3 mice) were used and brain tissue was immediately dissected and used for TRAP RNA purifications as 
450 previously described (Heiman et al., 2008). RNA quality was assessed using Bioanalyzer Pico

451 Chips (Agilent, 5067-1513) and quantified using Quant-iT RiboGreen RNA assay kit (Thermo

452 Fisher Scientific R11490). Libraries were prepared using Clonetech SMARTer Pico with

453 ribodepletion and Illumina HiSeq to 50NT single end reads. Sequencing was performed at the

454 MIT BioMicroCenter.

\section{Sequencing Data Analysis}

The raw fastq data of 50-bp single-end sequencing reads were aligned to the mouse

457 mm10 reference genome using STAR 2.4.0 RNA-Seq aligner (Dobin et al., 2013). The mapped

458 reads were processed by htseq-count of HTSeq software (Anders et al., 2015) with mm10 gene

459 annotation to count the number of reads mapped to each gene. The Cuffquant module of the

460 Cufflinks software (Trapnell et al., 2010) was used to calculate gene FPKM (Fragments Per

461 Kilobase of transcript per Million mapped reads) values. Gene differential expression test

462 between different animal groups was performed using DESeq2 package (Love et al., 2014)

463 with the assumption of negative binomial distribution for RNA-Seq data. Genes with adjusted p-

464 value $<0.05$ are chosen as differentially expressed genes. All analyses were performed using

465 genes with FPKM $>$ 1, which we considered as the threshold of expression (Figure 2- source 466 data).

\section{Sequencing Pathway and Motif Analysis}

Functional annotation clustering was performed using DAVID v6.7 (Huang da et al.,

469 2009). Gene ontology (GO) analysis was performed using AdvaitaBio iPathway guide V.v1702.

470 Enrichment vs. perturbation analysis was performed by AdvaitaBio iPathway guide V.v1702 and

471 allows comparison of pathway output perturbation and cumulative gene set expression changes.

472 In brief, the enrichment analysis is a straightforward gene-set enrichment over representation 
473 analysis (ORA) considering the number of differentially expressed genes (DEGs) that are

474 assigned to a given pathway. The enrichment value is expressed as a proportion of enriched

475 members to total genes in a defined pathway and a p-value (Fisher) is calculated for this score,

476 however false positives have been reported at up to $10 \%$ with this method (Draghici et al., 2007).

477 Perturbation, on the other hand, uses pathway data that applies relationships between gene

478 products rather than only using a list. Perturbation assigns an impact score based on a

479 mathematical model that captures the entire topology of the pathway and uses it to calculate how

480 changes in the expression of each gene in the pathway would perturb the absolute output of the

481 pathway (Draghici et al., 2007). Then, these gene perturbations are combined into a total

482 perturbation for the entire pathway and a p-value is calculated by comparing the observed value

483 with what is expected by chance. Motif analyses were performed using SignalP (v5.0; Almagro

484 Armenteros et al., 2019) and TMHMM (v2.0; Sonnhammer et al., 1998).

Transmission Electron Microscopy

All tissue processing, sectioning, and imaging was carried out at the Conventional

487 Electron Microscopy Facility at Harvard Medical School. Forebrain tissues were fixed in 2.5\%

488 Glutaraldehyde/2\% Paraformaldehyde in $0.1 \mathrm{M}$ sodium cacodylate buffer ( $\mathrm{pH} 7.4)$. They were

489 then washed in $0.1 \mathrm{M}$ cacodylate buffer and postfixed with $1 \%$ Osmiumtetroxide $(\mathrm{OsO} 4) / 1.5 \%$

490 Potassiumferrocyanide $\left(\mathrm{KFeCN}_{6}\right)$ for one hour, washed in water three times and incubated in $1 \%$

491 aqueous uranyl acetate for one hour. This was followed by two washes in water and subsequent

492 dehydration in grades of alcohol (10 minutes each; 50\%, 70\%, 90\%, 2x10min 100\%). Samples

493 were then incubated in propyleneoxide for one hour and infiltrated overnight in a 1:1 mixture of

494 propyleneoxide and TAAB Epon (Marivac Canada Inc. St. Laurent, Canada). The following day,

495 the samples were embedded in TAAB Epon and polymerized at 60 degrees $\mathrm{C}$ for 48 hours. 
Ultrathin sections (about 80nm) were cut on a Reichert Ultracut-S microtome, and picked up

497 onto copper grids stained with lead citrate. Sections were examined in a JEOL 1200EX

498 Transmission electron microscope or a TecnaiG ${ }^{2}$ Spirit BioTWIN. Images were recorded with an

499 AMT 2k CCD camera.

500

501

502

503

504

505

506

507

508

509

510

511

512

513

514 515 mitochondria.

\section{$\underline{\text { Seahorse Metabolic Analysis }}$}

\section{Glycogen and Mitochondrial Quantification}

Glycogen and mitochondrial quantification was performed by hand using the ImageJ plugin FIJI (Schindelin et al., 2012, Schneider et al., 2012). Percentages were calculated by dividing the area of interest by the total area of $\mathrm{ChP}$ epithelial cell within the field of view. No other cell types were included in the analysis. For each condition, analyses were performed across multiple individual animals ( $\mathrm{N}=3$ for each age). From each animal, 10-20 fields of view were imaged at 3,000x for glycogen analysis and 5-10 fields of view were imaged at 3,000x for mitochondrial analysis. Each different field of view represented a unique cell or cells, and fields of view were chosen such that both the apical and basal surfaces of the cell were visible. For mitochondrial distribution, a custom MatLab (v.2018) code was written to extract the centroid from mitochondria data traced in ImageJ ROIs (Supplementary file). Then a distance transformation was performed from each mitochondrion centroid to the hand-traced apical or basal surfaces. The shortest distance was extracted to calculate the apical: basal proximity ratio, such that $1=$ on the apical surface and $0=$ on the basal surface. The analyses included a total of 1747 adult mitochondria, 2241 P7 mitochondria, 2257 P0 mitochondria, and 1123 embryonic

ChP explants were dissected in HBSS (Fisher, SH30031FS) and maintained on wet ice 
until plated. Only the posterior leaflet of the P0, P7, and adult ChP was retained for analysis due to empirically determined limitations of the oxygen availability in the XFe96 Agilent Seahorse system. Tissue explants were plated on Seahorse XFe96 spheroid microplates (Agilent, 102905-

521 100) coated with Cell TAK (Corning), in Seahorse XF Base Medium (Agilent, 102353-100)

522 supplemented with $0.18 \%$ glucose, $1 \mathrm{mM}$ L-glutamine, and $1 \mathrm{mM}$ pyruvate at $\mathrm{pH} 7.4$ and 523 incubated for 1 hour at $37^{\circ} \mathrm{C}$ in a non- $\mathrm{CO}_{2}$ incubator. Extracellular acidification rates (ECAR) 524 and oxygen consumption rates (OCR) were measured via the Cell Mito Stress Test (Agilent, 525 103015-100) with a Seahorse XFe96Analyzer (Agilent) following the manufacturer's protocols.

526 Data were processed using Wave software (Agilent). ATP production was calculated as the 527 difference in OCR measurements before and after oligomycin injection, as described by the 528 manufacturer's protocol (Agilent, 103015-100). The Cell Mito Stress test was performed 2-5 529 independent times. The individual analyses were performed by averaging the readings from both 530 the right and left hemisphere lateral ventricle $\mathrm{ChP}$ for each individual. Data were normalized by 531 Calcein-AM ( $2 \mu \mathrm{M}$ in PBS, Life Technologies L-3224) fluorescence measured at the end of the 532 assay. Data are presented normalized to the adult levels for each assay to account for any 533 experimental variability.

$534 \quad$ High $\mathrm{K}^{+}$challenge study

Fresh LV ChPs were collected from P4 pups and adult mice in room temperature HBSS and glued down onto imaging dishes with coverslip bottom. The tissues were incubated at $37^{\circ} \mathrm{C}$ 537 with Calcein-AM (Invitrogen L3224; $1: 200$ ) for $10 \mathrm{~min}$ and then rinsed with $37^{\circ} \mathrm{C}$ artificial CSF 538 (aCSF: $119 \mathrm{mM} \mathrm{NaCl}, 2.5 \mathrm{mM} \mathrm{KCl}, 26 \mathrm{mM} \mathrm{NaHCO}, 1 \mathrm{mM} \mathrm{NaH} \mathrm{PO}_{4}, 11 \mathrm{mM}$ glucose, with 539 fresh $2.0 \mathrm{mM}$ magnesium chloride and $2.8 \mathrm{mM}$ calcium chloride). The tissues were soaked in $540 \quad 1.8 \mathrm{ml}$ aCSF at the beginning of each imaging session and allowed to stabilize for 10min. One Z- 
541 stack was acquired to reflect the baseline cell volume. Then a 10x $\mathrm{KCl}$ solution in aCSF was

542 spiked into the bath to make the final bath $\mathrm{K}^{+}$concentration $50 \mathrm{mM}$ immediately before imaging

543 subsequent continued. A total of five 3D Z-stacks were acquired throughout a 10-min imaging

544 session to capture changes in cellular volume over time. Each stack took less than 30 s to

545 minimize changes in cell volume from the beginning to the end of each stack. All imaging

546 studies were carried out at $37^{\circ} \mathrm{C}$. Image stacks were imported into Imaris (Bitplane) software.

547 Individual epithelial cells were identified by shape. Cells with discrete borders that were present

548 at all timepoints and had dark pixels both above and below them in $\mathrm{Z}$ for the whole timecourse

549 were selected a priori and then traced by hand using the "Surpass" functionality to create a 3D

550 surface volume through all Z stacks based on Calcein-AM uptake signal. Due to known $\mathrm{Z}$-step

551 distance and interpolation between the planes, Imaris calculated the number of voxels for each

552 cell. This analysis was then repeated for the same cell throughout the timecourse. We verified

553 manually that the cell was the same individual based on the topology of the surrounding cells,

554 allowing for adjustment for any $x-y$ drifting that occurred. The relative volume was calculated as

$555 \mathrm{dV} / \mathrm{V}_{0}$ for each timepoint $(\mathrm{t})$ where $\mathrm{V}_{0}$ is the initial volume of the cell, $\mathrm{t}$ is each subsequent

556 timepoint after addition of challenge, and $\mathrm{dV}=\mathrm{Vt}-\mathrm{V}_{0}$.

$557 \quad$ Tissue processing

558 Samples were fixed in 4\% paraformaldehyde (PFA). For cryosectioning, samples were 559 incubated in the following series of solutions: $10 \%$ sucrose, $20 \%$ sucrose, $30 \%$ sucrose, $1: 1$ 560 mixture of 30\% sucrose and OCT (overnight), and OCT (1 hour). Samples were frozen in OCT.

$561 \quad$ Immunostaining

562 Cryosections were blocked and permeabilized (0.3\% Triton-X-100 in PBS; 5\% serum),

563 incubated in primary antibodies overnight and secondary antibodies for 2 hours. Sections were 
$\mathrm{Xu}$ and Fame, et al. 26

564 counterstained with Hoechst 33342 (Invitrogen H3570, 1:10000) and mounted using

565 Fluoromount-G (SouthernBiotech). The following primary antibodies were used: chicken anti-

566 GFP (Abcam ab13970; 1:1000), mouse anti-Aqp1 (Santa Cruz sc-32737; 1:100), rabbit anti-

567 CHD4 (Abcam ab72418, 1:200), rabbit anti-NKCC1 (Abcam ab59791; 1:500), rat anti-HA

568 (Roche 11867423001; 1:1000). Secondary antibodies were selected from the Alexa series

569 (Invitrogen, 1:500). Images were acquired using Zeiss LSM880 confocal microscope with 20x 570 objective.

$571 \quad \underline{\text { Co-IP }}$

572 Tissues were homogenized in NET buffer $(150 \mathrm{mM} \mathrm{NaCl}, 10 \mathrm{mM}$ Tris 8.0, 5mM EDTA, $573 \quad 10 \%$ glycerol and $2 \%$ Triton-100) supplemented with protease inhibitors. Protein concentration 574 was determined by BCA assay (Thermo Scientific 23227). Lysates with same amount of total 575 protein $\left(250-1000 \mu \mathrm{g}\right.$ based on experiments) were pre-cleared at $4^{\circ} \mathrm{C}$ for $2 \mathrm{hr}$ with Protein $\mathrm{G}$ 576 agarose and then incubated with desired antibody or control antibody at $4^{\circ} \mathrm{C}$ overnight (no beads

577 present during antibody incubation). Protein G agarose beads were added to lysate-antibody 578 mixture after overnight incubation for $2 \mathrm{hr}$. Beads were washed thoroughly and then eluted by 579 boiling in 2\% SDS. ChP tissues were pooled across 7 litters of P0 pups and 30 adults to achieve 580 sufficient protein for Co-IP.

$581 \quad$ Immunoblotting

582 Tissues were homogenized in RIPA buffer supplemented with protease and phosphatase 583 inhibitors. Protein concentration was determined by BCA assay (Thermo Scientific 23227). 584 Samples were denatured in $2 \%$ SDS with 2-mercaptoethanol by heating at $37^{\circ} \mathrm{C}$ (for $\mathrm{NKCC} 1$ ) or $58595^{\circ} \mathrm{C}$ (for CHD4 and other NuRD complex proteins) for 5 minutes. Equal amounts of proteins 586 were loaded and separated by electrophoresis in a 4-15\% gradient polyacrylamide gel (BioRad 

\#1653320) or NuPAGE 4-12\% Bis-Tris gel (Invitrogen \#NP0322), transferred to a nitrocellulose membrane $(250 \mathrm{~mA}, 1.5$ hours, on ice), blocked in filtered 5\% BSA or milk in TBST, incubated with primary antibodies overnight at $4^{\circ} \mathrm{C}$ followed by HRP conjugated secondary antibodies

590 (1:5000) for 1 hour, and visualized with ECL substrate. For phosphorylated protein analysis, the 591 phospho-proteins were probed first, and then blots were stripped (Thermo Scientific 21059) and 592 reprobed for total proteins. For co-IP protein analysis, TrueBlot secondary antibody (eBioscience 593 18-8816-33) was used to detect only non-denatured IgG and avoid background signal from IP 594 antibody. The following primary antibodies were used: rabbit anti-NKCC1 (Abcam ab59791; 595 1:1000), rabbit anti-pNKCC1 (EMD Millipore ABS1004; 1:1000), rabbit anti-ATP1a1 (Upstate C464.6/05-369; 1:250, goat-anti-klotho (R\&D AF1819-sp; 1:200), rabbit anti-GAPDH (Sigma

597 G9545; 1:10000), mouse anti-HA (Abcam ab130275; 1:1000), rabbit anti-CHD4 (Abcam ab72418; 1:2000), rabbit anti-MBD3 (Abcam ab157464; 1:1000), rabbit anti-HDAC1 (Abcam ab7028; 1:2000), mouse anti-HDAC2 (Abcam 51832; 1:2000).

602 was isolated using the MirVana miRNA isolation kit (Invitrogen AM1561) following 603 manufacturer's specifications without miRNA enrichment step. Extracted RNA was quantified 604 spectrophotometrically and 100ng was reverse-transcribed into cDNA using the High Capacity 605 cDNA Reverse Transcription kit (Applied Biosystems \#4368814) following manufacturer's 606 specifications. RT-qPCRs were performed in duplicate using Taqman Gene Expression Assays 607 and Taqman Gene Expression Master Mix (Applied Biosystems) with GAPDH as an internal 608 control. Cycling was executed using the StepOnePlus Real-Time PCR System (Invitrogen) and 609 analysis of relative gene expression was performed using the $2^{-\Delta \Delta C T}$ method. Technical replicates 
were averaged for their cycling thresholds and further calculations were performed with those

611 means.

612 In utero intracerebroventricular injection (ICV)

613 Timed pregnant mice (E14.5) were deeply anesthetized by isoflurane and placed on warm

614 pads. Laparotomy was performed and AAV solution was delivered into the lateral ventricle of

615 each embryo using glass capillary pipettes. The abdominal incision was then sutured. Meloxicam

616 analgesia was longitudinally delivered according to IACUC protocol.

617 Intraventricular kaolin injection in postnatal pups

618 Postnatal day 4 pups (P4) were deeply anesthetized by hypothermia. $1 \mu$ l of sterile kaolin

619 solution $(25 \%$ in PBS) was delivered into the left lateral ventricle using glass capillary pipettes.

620 The lateral ventricle location was determined as in between bregma and lambda, and $1 \mathrm{~mm}$ from

621 mid-line. The pups were then warmed and returned to the dam.

$622 \quad$ AAV production

623 The original AAV-NKCC1 plasmid was purchased from Addgene (pcDNA3.1 HA CFP

624 hNKCC1 WT (NT15-H) was a gift from Biff Forbush: Addgene plasmid \# 49077;

625 http://n2t.net/addgene:49077; RRID:Addgene_49077). The plasmid carries an 3xHA tag at the

626 N-terminal of NKCC1 to allow detection and separation from endogenous NKCC1. The CFP tag

627 was removed by BsaI digestion to reduce insert size for AAV production. Virus production and

628 purification were performed by the Penn Vector Core. Due to the very large size of the plasmid

629 we experienced variable infection efficiency. All mice receiving AAV-NKCC1 were analyzed

630 for HA expression after every experiment to confirm infection efficiency. AAV-GFP and AAV-

631 Cre were purchased from BCH viral core at Boston Children's Hospital. 
$\mathrm{Xu}$ and Fame, et al. 29

644 deliver a constant rate infusion of 1-4 uL/minute. The syringe was connected via pressure tubing 645 to hemostasis valve Y connector (Qosina, NY). A fiberoptic ICP sensor (Fiso Technologies Inc,

646 Québec, Canada) was inserted through the other port of the rotating hemostat and then into 0.55

$647 \mathrm{~mm}$ diameter catheter until the sensor was flush with the catheter's distal tip. The entire 648 apparatus and tubing was carefully screened to ensure the absence of air bubbles. Adult mice 649 were then deeply anesthetized, placed on a warm pad, and head-fixed with ear bars. The distal 650 end of the infusion device (catheter with fiberoptic sensor) was placed inside lateral ventricle ($6510.4 \mathrm{~mm}$ (anterior-posterior) and $1.2 \mathrm{~mm}$ (medial-lateral) with respect to Bregma, and a depth of 2 $652 \mathrm{~mm}$ from the outer edge of the skull); the catheter was then sealed with Vetbond (3M, 653 Minnesota). Intraventricular access and water-tight seal was confirmed by observation of arterial 654 and respiratory waveforms in the ICP signal and a transient rise in ICP upon gentle compression 
of the abdomen and thorax. Two minutes of baseline ICP were recorded before initiating the

656 infusion of aCSF. As the infusion proceeded, careful observation was made of the mouse's

657 respiratory rate. After the ICP level reached a new plateau, the infusion was discontinued. The

658 procedure was terminal. Parameters of the Marmarou model of CSF dynamics for constant rate

659 infusions were estimated by a non-linear least squares fit of the model to the ICP data (Czosnyka

660 et al., 2012)

$$
I C P(t)=\frac{\left[i_{\text {infusion }}+\frac{I C P_{\text {baseline }}-p_{0}}{R_{C S F}}\right] \cdot\left[\text { ICP }_{\text {baseline }}-p_{0}\right]}{\frac{I C P_{\text {baseline }}-p_{0}}{R_{C S F}}+i_{\text {infusion }} \cdot\left[e^{-\frac{\left[i_{\text {infusion }}+\frac{I C P_{\text {baseline }}-p_{0}}{R_{C S F}}\right]}{C_{i}} t}\right]}
$$

661 where $\mathrm{i}_{\text {infusion }}$ is the rate of infusion, $I C P_{\text {baseline }}$ is the ICP level before infusion, $p_{0}$ is a pressure in

662 the storage arm of the model, $R_{C S F}$ is the resistance to CSF outflow, and $C_{i}$ is the compliance 663 coefficient.

\section{QUANTIFICATION AND STATISTICAL ANALYSIS}

Biological replicates $(\mathrm{N})$ were defined as samples from distinct individual animals, analyzed either in the same experiment or within multiple experiments, with the exception when

667 individual animal could not provide sufficient sample (i.e. CSF), in which case multiple animals

668 were pooled into one biological replicate and the details are stated in the corresponding figure

669 legends. Statistical analyses were performed using Prism 7 or R. Outliers were excluded using

670 ROUT method $(\mathrm{Q}=1 \%)$. Appropriate statistical tests were selected based on the distribution of

671 data, homogeneity of variances, and sample size. The majority of the analyses were done using

672 One-way ANOVA with multiple comparison correction (Sidak) or Welch's unpaired t-test,

673 except for Fig. 1E-G, and Fig. 1I-J where the analysis was done by Welch's ANOVA with

674 Dunnett's T3 multiple comparison test, and Fig. 1L where the analysis was done using 
675 Kolmogorov-Smirnov test. F tests or Bartlett's tests were used to assess homogeneity of

676 variances between data sets. Parametric tests (t-test, ANOVA) were used only if data were

677 normally distributed and variances were approximately equal. Otherwise, nonparametric

678 alternatives were chosen. Data are presented as means \pm standard deviation (SD). If multiple

679 measurements were taken from a single individual, data are presented as means \pm standard errors

680 of the mean (SEMs). Please refer to figure legends for sample size. $p$ values $<0.05$ were

681 considered significant $(* p<0.05, * * p<0.01, * * * p<0.001, * * * * p<0.0001)$. Exact $\mathrm{p}$ values

682 can be found in the figure legends. $\mathrm{P}$ values are also marked in the figures where space allows. 
$\mathrm{Xu}$ and Fame, et al. 32

\section{REFERENCES:}

Almagro Armenteros JJ, Tsirigos KD, Sonderby CK, Petersen TN, Winther O, Brunak S, von Heijne G, Nielsen H (2019) SignalP 5.0 improves signal peptide predictions using deep neural networks. Nature biotechnology 37:420-423.

Amin H, Marinaro F, De Pietri Tonelli D, Berdondini L (2017) Developmental excitatory-toinhibitory GABA-polarity switch is disrupted in 22q11.2 deletion syndrome: a potential target for clinical therapeutics. Scientific reports 7:15752.

Anders S, Pyl PT, Huber W (2015) HTSeq--a Python framework to work with high-throughput sequencing data. Bioinformatics 31:166-169.

Antila S, Karaman S, Nurmi H, Airavaara M, Voutilainen MH, Mathivet T, Chilov D, Li Z, Koppinen T, Park JH, Fang S, Aspelund A, Saarma M, Eichmann A, Thomas JL, Alitalo K (2017) Development and plasticity of meningeal lymphatic vessels. The Journal of experimental medicine 214:3645-3667.

Aquilina K, Pople IK, Sacree J, Carter MR, Edwards RJ (2012) The constant flow ventricular infusion test: a simple and useful study in the diagnosis of third ventriculostomy failure. Journal of neurosurgery 116:445-452.

Banerjee A, Rikhye RV, Breton-Provencher V, Tang X, Li C, Li K, Runyan CA, Fu Z, Jaenisch R, Sur M (2016) Jointly reduced inhibition and excitation underlies circuit-wide changes in cortical processing in Rett syndrome. Proceedings of the National Academy of Sciences of the United States of America 113:E7287-E7296.

Bhargava P, Schnellmann RG (2017) Mitochondrial energetics in the kidney. Nature reviews Nephrology 13:629-646.

Cserr H (1965) Potassium exchange between cerebrospinal fluid, plasma, and brain. The American journal of physiology 209:1219-1226.

Czosnyka M, Czosnyka Z, Agarwal-Harding KJ, Pickard JD (2012) Modeling of CSF dynamics: legacy of Professor Anthony Marmarou. Acta neurochirurgica Supplement 113:9-14.

Damkier HH, Brown PD, Praetorius J (2013) Cerebrospinal fluid secretion by the choroid plexus. Physiological reviews 93:1847-1892.

Darman RB, Forbush B (2002) A regulatory locus of phosphorylation in the N terminus of the Na-K-Cl cotransporter, NKCC1. The Journal of biological chemistry 277:37542-37550.

Deidda G, Parrini M, Naskar S, Bozarth IF, Contestabile A, Cancedda L (2015) Reversing excitatory GABAAR signaling restores synaptic plasticity and memory in a mouse model of Down syndrome. Nature medicine 21:318-326.

Delpire E, Gagnon KB (2019) Elusive role of the Na-K-2Cl cotransporter in the choroid plexus. American journal of physiology Cell physiology 316:C522-C524.

Dobin A, Davis CA, Schlesinger F, Drenkow J, Zaleski C, Jha S, Batut P, Chaisson M, Gingeras TR (2013) STAR: ultrafast universal RNA-seq aligner. Bioinformatics 29:15-21.

Draghici S, Khatri P, Tarca AL, Amin K, Done A, Voichita C, Georgescu C, Romero R (2007) A systems biology approach for pathway level analysis. Genome research 17:1537-1545. 
$\mathrm{Xu}$ and Fame, et al. 33

Eide PK (2018) The pathophysiology of chronic noncommunicating hydrocephalus: lessons from continuous intracranial pressure monitoring and ventricular infusion testing. Journal of neurosurgery 129:220-233.

Fame RM, Lehtinen MK (2020) Emergence and Developmental Roles of the Cerebrospinal Fluid System. Developmental Cell 52:261-275.

Fencl V, Miller TB, Pappenheimer JR (1966) Studies on the respiratory response to disturbances of acid-base balance, with deductions concerning the ionic composition of cerebral interstitial fluid. The American journal of physiology 210:459-472.

Furey CG, Choi J, Jin SC, Zeng X, Timberlake AT, Nelson-Williams C, Mansuri MS, Lu Q, Duran D, Panchagnula S, Allocco A, Karimy JK, Khanna A, Gaillard JR, DeSpenza T, Antwi P, Loring E, Butler WE, Smith ER, Warf BC, Strahle JM, Limbrick DD, Storm PB, Heuer G, Jackson EM, Iskandar BJ, Johnston JM, Tikhonova I, Castaldi C, LopezGiraldez F, Bjornson RD, Knight JR, Bilguvar K, Mane S, Alper SL, Haider S, Guclu B, Bayri Y, Sahin Y, Apuzzo MLJ, Duncan CC, DiLuna ML, Gunel M, Lifton RP, Kahle KT (2018) De Novo Mutation in Genes Regulating Neural Stem Cell Fate in Human Congenital Hydrocephalus. Neuron 99:302-314 e304.

Gato A, Alonso MI, Martin C, Carnicero E, Moro JA, De la Mano A, Fernandez JM, Lamus F, Desmond ME (2014) Embryonic cerebrospinal fluid in brain development: neural progenitor control. Croatian medical journal 55:299-305.

Gilmore JH, Kang C, Evans DD, Wolfe HM, Smith JK, Lieberman JA, Lin W, Hamer RM, Styner M, Gerig G (2010) Prenatal and neonatal brain structure and white matter maturation in children at high risk for schizophrenia. The American journal of psychiatry 167:1083-1091.

Goodman JV, Bonni A (2019) Regulation of neuronal connectivity in the mammalian brain by chromatin remodeling. Current opinion in neurobiology 59:59-68.

Haddad MR, Donsante A, Zerfas P, Kaler SG (2013) Fetal Brain-directed AAV Gene Therapy Results in Rapid, Robust, and Persistent Transduction of Mouse Choroid Plexus Epithelia. Molecular therapy Nucleic acids 2:e101.

Hamann S, Herrera-Perez JJ, Zeuthen T, Alvarez-Leefmans FJ (2010) Cotransport of water by the $\mathrm{Na}+-\mathrm{K}+-2 \mathrm{Cl}(-)$ cotransporter $\mathrm{NKCC1}$ in mammalian epithelial cells. The Journal of physiology 588:4089-4101.

He Q, Nomura T, Xu J, Contractor A (2014) The developmental switch in GABA polarity is delayed in fragile $\mathrm{X}$ mice. The Journal of neuroscience : the official journal of the Society for Neuroscience 34:446-450.

Heiman M, Schaefer A, Gong S, Peterson JD, Day M, Ramsey KE, Suarez-Farinas M, Schwarz C, Stephan DA, Surmeier DJ, Greengard P, Heintz N (2008) A translational profiling approach for the molecular characterization of CNS cell types. Cell 135:738-748.

Huang da W, Sherman BT, Lempicki RA (2009) Systematic and integrative analysis of large gene lists using DAVID bioinformatics resources. Nature protocols 4:44-57.

Hudry E, Dashkoff J, Roe AD, Takeda S, Koffie RM, Hashimoto T, Scheel M, Spires-Jones T, Arbel-Ornath M, Betensky R, Davidson BL, Hyman BT (2013) Gene transfer of human 
$\mathrm{Xu}$ and Fame, et al. 34

Apoe isoforms results in differential modulation of amyloid deposition and neurotoxicity in mouse brain. Science translational medicine 5:212ra161.

Hyde TM, Lipska BK, Ali T, Mathew SV, Law AJ, Metitiri OE, Straub RE, Ye T, Colantuoni C, Herman MM, Bigelow LB, Weinberger DR, Kleinman JE (2011) Expression of GABA signaling molecules $\mathrm{KCC} 2$, NKCC1, and GAD1 in cortical development and schizophrenia. The Journal of neuroscience : the official journal of the Society for Neuroscience 31:11088-11095.

Kahle KT, Kulkarni AV, Limbrick DD, Jr., Warf BC (2016) Hydrocephalus in children. Lancet 387:788-799.

Kaler SG (1994) Menkes disease. Advances in pediatrics 41:263-304.

Keep RF, Jones HC (1990) A morphometric study on the development of the lateral ventricle choroid plexus, choroid plexus capillaries and ventricular ependyma in the rat. Brain research Developmental brain research 56:47-53.

Lalou AD, Czosnyka M, Donnelly J, Pickard JD, FmedSci, Nabbanja E, Keong NC, Garnett M, Czosnyka ZH (2018) Cerebral autoregulation, cerebrospinal fluid outflow resistance, and outcome following cerebrospinal fluid diversion in normal pressure hydrocephalus. Journal of neurosurgery 130:154-162.

Li Q, Aalling NN, Forstera B, Erturk A, Nedergaard M, Mollgard K, Xavier ALR (2020) Aquaporin 1 and the $\mathrm{Na}(+) / \mathrm{K}(+) / 2 \mathrm{Cl}(-)$ cotransporter 1 are present in the leptomeningeal vasculature of the adult rodent central nervous system. Fluids and barriers of the CNS $17: 15$.

Liddelow SA, Dziegielewska KM, Ek CJ, Habgood MD, Bauer H, Bauer HC, Lindsay H, Wakefield MJ, Strazielle N, Kratzer I, Mollgard K, Ghersi-Egea JF, Saunders NR (2013) Mechanisms that determine the internal environment of the developing brain: a transcriptomic, functional and ultrastructural approach. PloS one 8:e65629.

LoTurco JJ, Owens DF, Heath MJ, Davis MB, Kriegstein AR (1995) GABA and glutamate depolarize cortical progenitor cells and inhibit DNA synthesis. Neuron 15:1287-1298.

Love MI, Huber W, Anders S (2014) Moderated estimation of fold change and dispersion for RNA-seq data with DESeq2. Genome biology 15:550.

Lun MP, Johnson MB, Broadbelt KG, Watanabe M, Kang YJ, Chau KF, Springel MW, Malesz A, Sousa AM, Pletikos M, Adelita T, Calicchio ML, Zhang Y, Holtzman MJ, Lidov HG, Sestan N, Steen H, Monuki ES, Lehtinen MK (2015) Spatially heterogeneous choroid plexus transcriptomes encode positional identity and contribute to regional CSF production. The Journal of neuroscience : the official journal of the Society for Neuroscience 35:4903-4916.

Madan CR (2015) Creating 3D visualizations of MRI data: A brief guide. F1000Research 4:466.

Madry C, Kyrargyri V, Arancibia-Carcamo IL, Jolivet R, Kohsaka S, Bryan RM, Attwell D (2018) Microglial Ramification, Surveillance, and Interleukin-1beta Release Are Regulated by the Two-Pore Domain K(+) Channel THIK-1. Neuron 97:299-312 e296.

Milhorat TH, Mosher MB, Hammock MK, Murphy CF (1970) Evidence for choroid-plexus absorption in hydrocephalus. The New England journal of medicine 283:286-289. 
$\mathrm{Xu}$ and Fame, et al. 35

Munk AS, Wang W, Bechet NB, Eltanahy AM, Cheng AX, Sigurdsson B, Benraiss A, Mae MA, Kress BT, Kelley DH, Betsholtz C, Mollgard K, Meissner A, Nedergaard M, Lundgaard I (2019) PDGF-B Is Required for Development of the Glymphatic System. Cell reports 26:2955-2969 e2953.

Netsky MG, Shuangshoti S (1975) The choroid plexus in health and disease. Charlottesville: University Press of Virginia.

Oreskovic D, Rados M, Klarica M (2017) Role of choroid plexus in cerebrospinal fluid hydrodynamics. Neuroscience 354:69-87.

Owens DF, Liu X, Kriegstein AR (1999) Changing properties of GABA(A) receptor-mediated signaling during early neocortical development. Journal of neurophysiology 82:570-583.

Pisella LI, Gaiarsa J-L, Diabira D, Zhang J, Khalilov I, Duan J, Kahle KT, Medina I (2019) Impaired regulation of $\mathrm{KCC} 2$ phosphorylation leads to neuronal network dysfunction and neurodevelopmental pathology. Science Signaling 12:eaay0300.

Rasmussen R, O'Donnell J, Ding F, Nedergaard M (2020) Interstitial ions: A key regulator of state-dependent neural activity? Progress in neurobiology 193:101802.

Razzaque MS (2008) Klotho and $\mathrm{Na}^{+}, \mathrm{K}+$-ATPase activity: solving the calcium metabolism dilemma? Nephrology, dialysis, transplantation : official publication of the European Dialysis and Transplant Association - European Renal Association 23:459-461.

Saunders NR, Dziegielewska KM, Møllgård K, Habgood MD (2018) Physiology and molecular biology of barrier mechanisms in the fetal and neonatal brain. The Journal of physiology 596:5723-5756.

Schafer DP, Lehrman EK, Kautzman AG, Koyama R, Mardinly AR, Yamasaki R, Ransohoff RM, Greenberg ME, Barres BA, Stevens B (2012) Microglia sculpt postnatal neural circuits in an activity and complement-dependent manner. Neuron 74:691-705.

Schindelin J, Arganda-Carreras I, Frise E, Kaynig V, Longair M, Pietzsch T, Preibisch S, Rueden C, Saalfeld S, Schmid B, Tinevez JY, White DJ, Hartenstein V, Eliceiri K, Tomancak P, Cardona A (2012) Fiji: an open-source platform for biological-image analysis. Nature methods 9:676-682.

Schneider CA, Rasband WS, Eliceiri KW (2012) NIH Image to ImageJ: 25 years of image analysis. Nature methods 9:671-675.

Schuler MH, Lewandowska A, Caprio GD, Skillern W, Upadhyayula S, Kirchhausen T, Shaw JM, Cunniff B (2017) Miro1-mediated mitochondrial positioning shapes intracellular energy gradients required for cell migration. Molecular biology of the cell 28:2159-2169.

Shaolin Z, Zhanxiang W, Hao X, Feifei Z, Caiquan H, Donghan C, Jianfeng B, Feng L, Shanghang S (2015) Hydrocephalus induced via intraventricular kaolin injection in adult rats. Folia neuropathologica 53:60-68.

Shen MD, Kim SH, McKinstry RC, Gu H, Hazlett HC, Nordahl CW, Emerson RW, Shaw D, Elison JT, Swanson MR, Fonov VS, Gerig G, Dager SR, Botteron KN, Paterson S, Schultz RT, Evans AC, Estes AM, Zwaigenbaum L, Styner MA, Amaral DG, Piven J, Hazlett HC, Chappell C, Dager S, Estes A, Shaw D, Botteron K, McKinstry R, Constantino J, Pruett J, Schultz R, Zwaigenbaum L, Elison J, Evans AC, Collins DL, 
Pike GB, Fonov V, Kostopoulos P, Das S, Gerig G, Styner M, Gu H, Piven J, Infant Brain Imaging Study N (2017) Increased Extra-axial Cerebrospinal Fluid in High-Risk Infants Who Later Develop Autism. Biological psychiatry 82:186-193.

Smith GM, Gallo G (2018) The role of mitochondria in axon development and regeneration. Developmental neurobiology 78:221-237.

Somasekharan S, Monette MY, Forbush B (2013) Functional expression of human NKCC1 from a synthetic cassette-based cDNA: introduction of extracellular epitope tags and removal of cysteines. PloS one 8:e82060.

Sonnhammer ELL, Heijne Gv, Krogh A (1998) A hidden Markov model for predicting transmembrane helices in protein sequences. In: In Proc of Sixth Int Conf on Intelligent Systems for Molecular Biology (Glasgow, J. et al., eds), pp 175-182 Menlo Park, CA: AAAI Press.

Sopjani M, Alesutan I, Dermaku-Sopjani M, Gu S, Zelenak C, Munoz C, Velic A, Foller M, Rosenblatt KP, Kuro-o M, Lang F (2011) Regulation of the Na+/K+ ATPase by Klotho. FEBS letters 585:1759-1764.

Spassky N, Merkle FT, Flames N, Tramontin AD, Garcia-Verdugo JM, Alvarez-Buylla A (2005) Adult ependymal cells are postmitotic and are derived from radial glial cells during embryogenesis. The Journal of neuroscience : the official journal of the Society for Neuroscience 25:10-18.

Steen RG, Mull C, McClure R, Hamer RM, Lieberman JA (2006) Brain volume in first-episode schizophrenia: systematic review and meta-analysis of magnetic resonance imaging studies. The British journal of psychiatry : the journal of mental science 188:510-518.

Steffensen AB, Oernbo EK, Stoica A, Gerkau NJ, Barbuskaite D, Tritsaris K, Rose CR, MacAulay N (2018) Cotransporter-mediated water transport underlying cerebrospinal fluid formation. Nature communications 9:2167.

Trapnell C, Williams BA, Pertea G, Mortazavi A, Kwan G, van Baren MJ, Salzberg SL, Wold BJ, Pachter L (2010) Transcript assembly and quantification by RNA-Seq reveals unannotated transcripts and isoform switching during cell differentiation. Nature biotechnology 28:511-515.

Vinchon M, Rekate H, Kulkarni AV (2012) Pediatric hydrocephalus outcomes: a review. Fluids and barriers of the CNS 9:18.

Vinje V, Eklund A, Mardal KA, Rognes ME, Stoverud KH (2020) Intracranial pressure elevation alters CSF clearance pathways. Fluids and barriers of the CNS 17:29.

Volpe JJ (2008) Neurology of the newborn. Philadelphia: Saunders/Elsevier.

Watanabe M, Zhang J, Mansuri MS, Duan J, Karimy JK, Delpire E, Alper SL, Lifton RP, Fukuda A, Kahle KT (2019) Developmentally regulated KCC2 phosphorylation is essential for dynamic GABA-mediated inhibition and survival. Science Signaling 12:eaaw9315.

Weiss K, Lazar HP, Kurolap A, Martinez AF, Paperna T, Cohen L, Smeland MF, Whalen S, Heide S, Keren B, Terhal P, Irving M, Takaku M, Roberts JD, Petrovich RM, Schrier Vergano SA, Kenney A, Hove H, DeChene E, Quinonez SC, Colin E, Ziegler A, Rumple 
Williams CJ, Naito T, Arco PG, Seavitt JR, Cashman SM, De Souza B, Qi X, Keables P, Von M, Jain M, Monteil D, Roeder ER, Nugent K, van Haeringen A, Gambello M, Santani A, Medne L, Krock B, Skraban CM, Zackai EH, Dubbs HA, Smol T, Ghoumid J, Parker MJ, Wright M, Turnpenny P, Clayton-Smith J, Metcalfe K, Kurumizaka H, Gelb BD, Baris Feldman H, Campeau PM, Muenke M, Wade PA, Lachlan K (2020) The CHD4-related syndrome: a comprehensive investigation of the clinical spectrum, genotype-phenotype correlations, and molecular basis. Genetics in medicine : official journal of the American College of Medical Genetics 22:389-397. Andrian UH, Georgopoulos K (2004) The chromatin remodeler Mi-2beta is required for CD4 expression and T cell development. Immunity 20:719-733.

Zeuthen T (1994) Cotransport of $\mathrm{K}+, \mathrm{Cl}$ - and $\mathrm{H} 2 \mathrm{O}$ by membrane proteins from choroid plexus epithelium of Necturus maculosus. The Journal of physiology 478 ( Pt 2):203-219.

Zeuthen T, Macaulay $\mathrm{N}$ (2012) Cotransport of water by $\mathrm{Na}(+)-\mathrm{K}(+)-2 \mathrm{Cl}(-)$ cotransporters expressed in Xenopus oocytes: NKCC1 versus NKCC2. The Journal of physiology 590:1139-1154.

905

Zhang Y, Huang G, Shornick LP, Roswit WT, Shipley JM, Brody SL, Holtzman MJ (2007) A transgenic FOXJ1-Cre system for gene inactivation in ciliated epithelial cells. American journal of respiratory cell and molecular biology 36:515-519. 

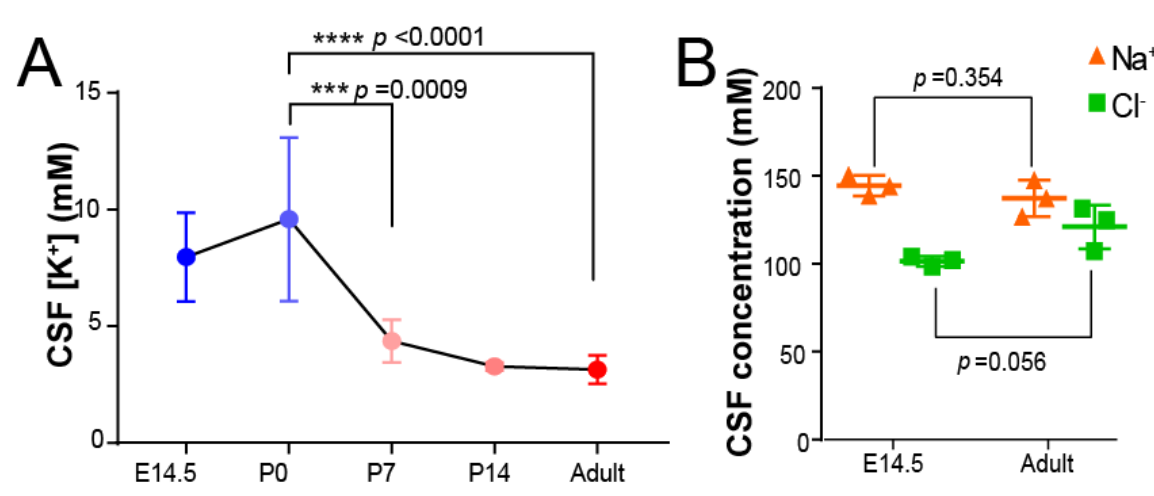

D

E16.5
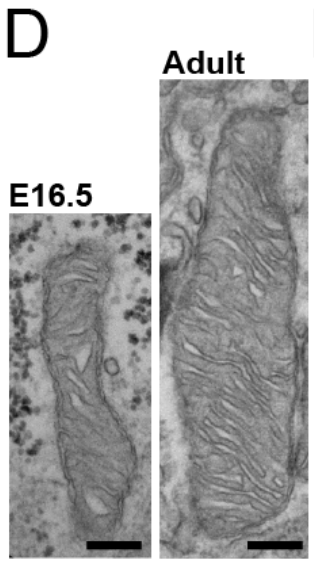

$E$
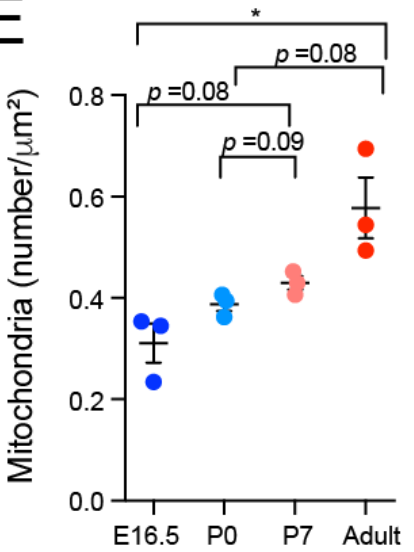

$\mathrm{H}$
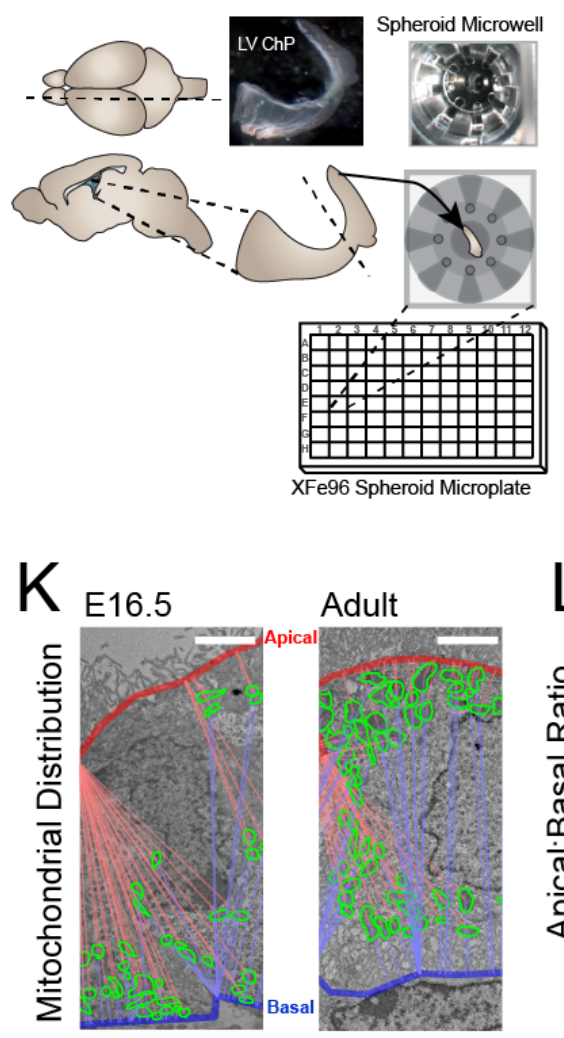

$\mathrm{L}$

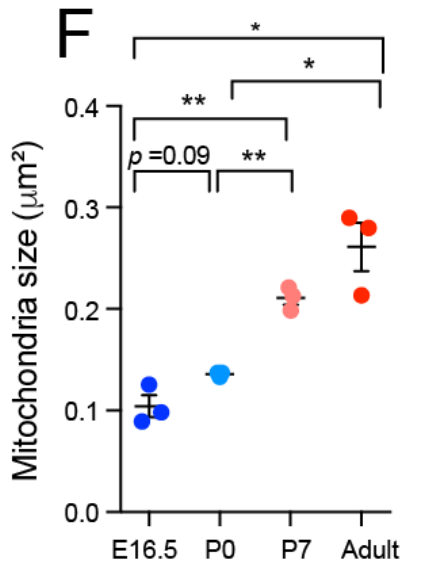

Basal Respiration

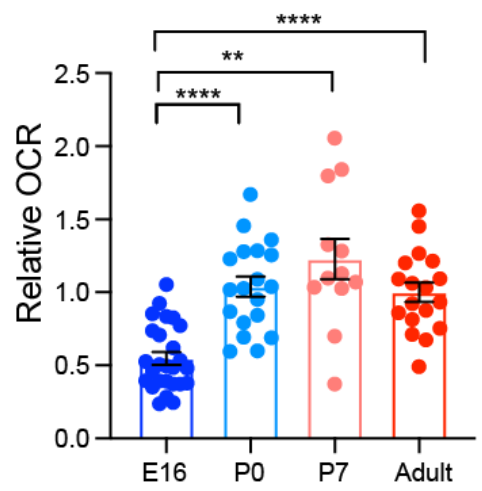

Mitochondrial Distribution

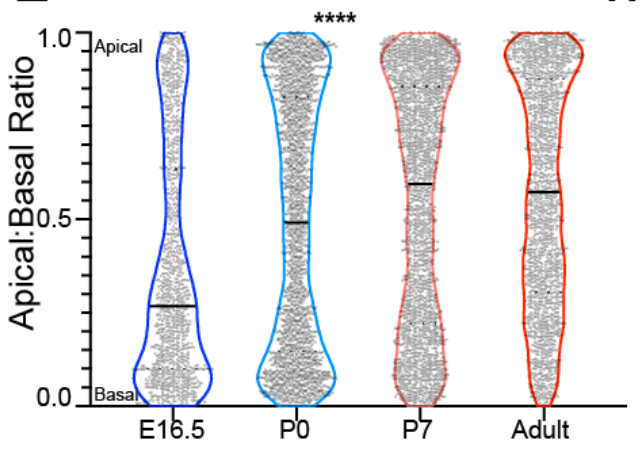

Figure 1
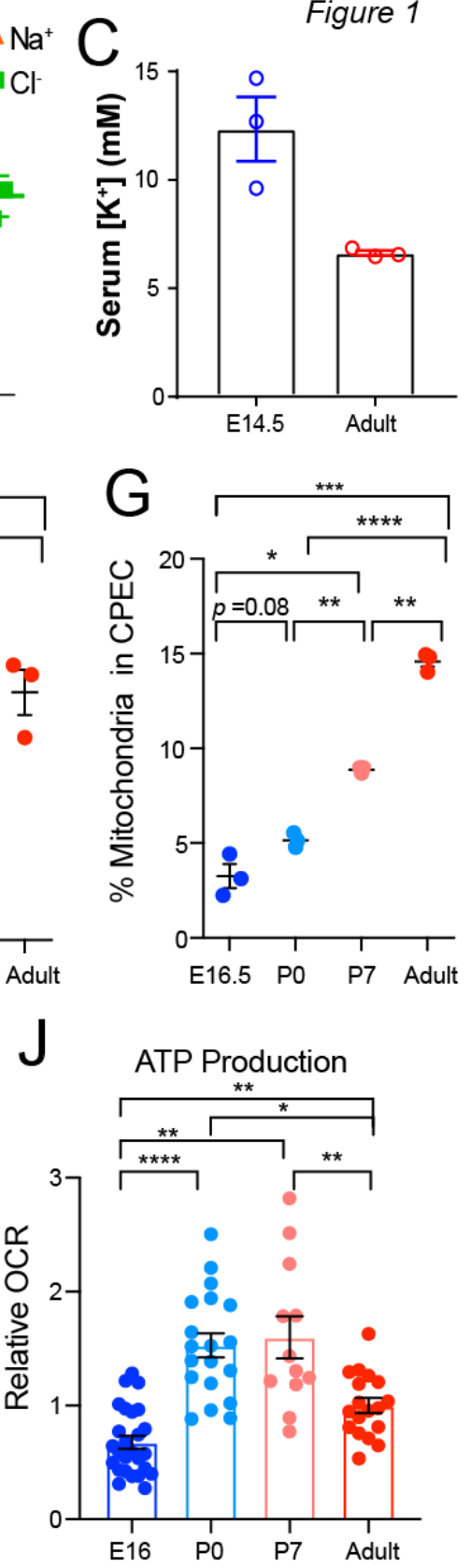

M. Cumulative

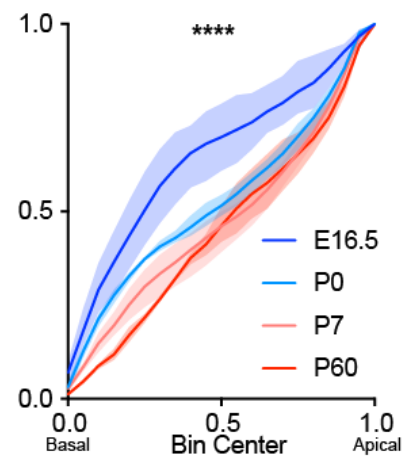


908 quantification of CSF $\left[\mathrm{K}^{+}\right] . \mathrm{N}=6, * * * * p<0.0001$ by one-way ANOVA. Sidak's test was used

909 for P0 vs. P7 and P0 vs. adult comparison. $* * * p=0.0009, * * * * p<0.0001$. (B) ICP-OES and

910 IC measurements of E14.5 and adult mouse CSF $\left[\mathrm{Na}^{+}\right]$and $\left[\mathrm{Cl}^{-}\right] . \mathrm{N}=3$; Welch's t-test. (C) ICP-

911 OES measurements of embryo vs. adult mouse serum $\left[\mathrm{K}^{+}\right] . \mathrm{N}=3$. (D) Transmission micrographs

912 of mitochondria in LVChP. (E-G) Quantification of mitochondrial number (E), area (F), and \%

913 area occupancy $(\mathbf{G})$ in ChP epithelial cells. $\mathrm{N}=3$ animals, 5-10 FOV per animal, ${ }^{*} p<0.05,{ }^{* *} p$

$914<0.01, * * * p<0.005, * * * * p<0.001$; Welch's t-test. (H) Schematic of explant-based Agilent

915 Seahorse XFe96 test. (I-J) Oxidative respiration metrics over development. ${ }^{*} p<0.05,{ }^{*} p<<$

$9160.01, * * * * p<0.0001$; Welch's ANOVA with Dunnett's T3 multiple comparison test. (K-L)

917 Mitochondrial distribution between the apical and basal surfaces (Apical: Basal proximity ratio).

$9181=$ apical surface. $0=$ basal surface. Solid line indicates median and dashed line indicates

919 upper/lower quartiles. **** $p<0.0001$; Kolmogorov-Smirnov test. (M) Cumulative distribution

920 of mitochondrial localization. Solid lines are the mean, shaded area represents the range. Scale

921 bar $(\mathrm{d})=250 \mathrm{~nm},(\mathrm{k})=2 \mu \mathrm{m}$. Unless otherwise noted, all quantitative data are presented as Mean $922 \pm$ SEM. 


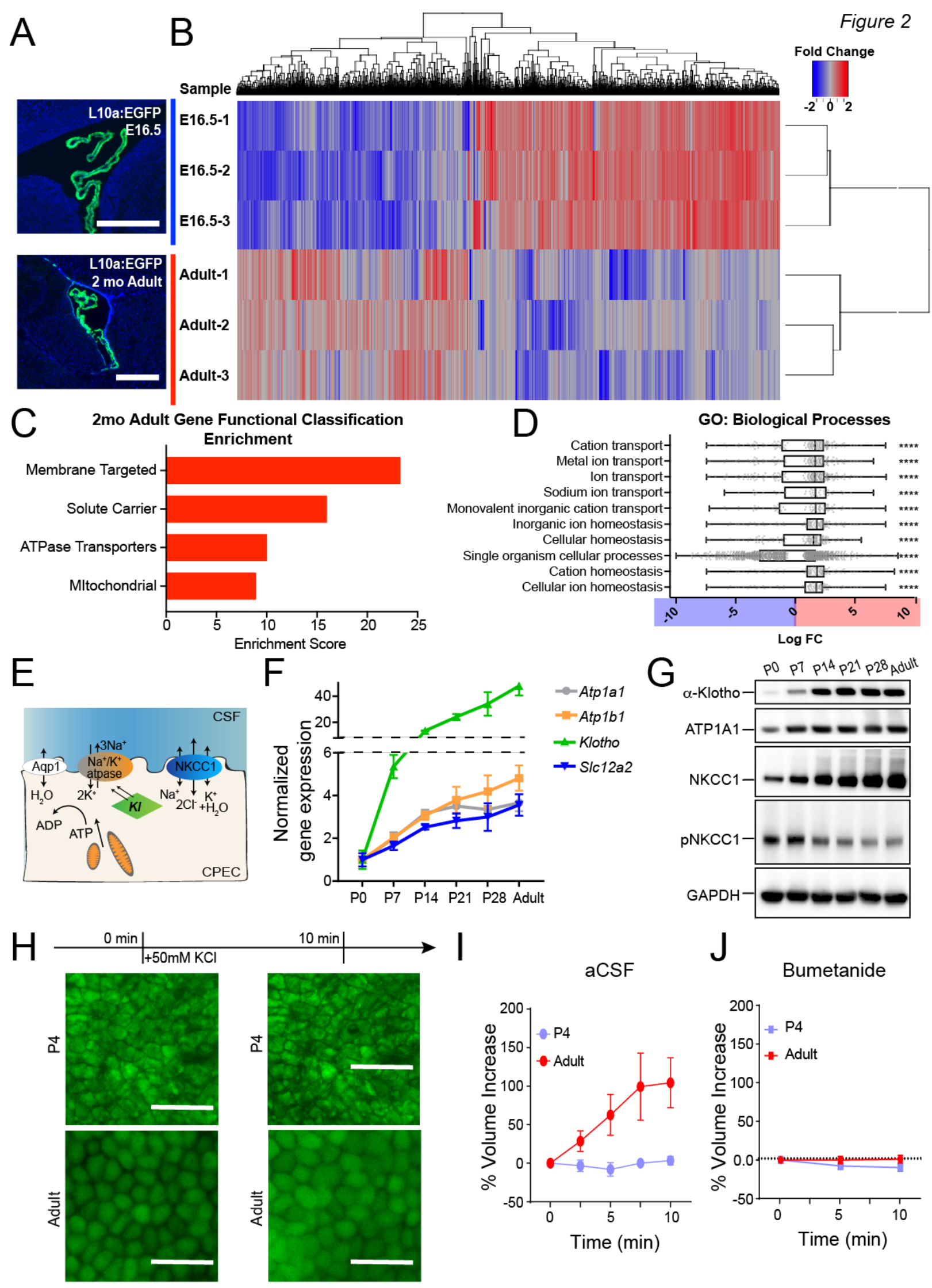


Fig. 2. Choroid plexus epithelial cells display age-dependent translation of ion and water

927 cells after Foxj1-Cre recombination in TRAP-BAC mice. (B) Heatmap and hierarchical

928 clustering of differentially expressed genes (adjusted $\mathrm{p}<0.05$ ). (C) Top 4 gene functional

929 clusters shown by DAVID to be enriched in Adult ChP epithelial cells over E16.5 ChP epithelial

930 cells. (D) Top 10 significantly enriched gene ontology (GO) terms for "Biological processes".

931 Plotted with boxes for quartiles and whiskers for $5^{\text {th }}$ and $95^{\text {th }}$ percentiles. The $\log _{10}$ fold change

932 (LogFC) is plotted for each expressed gene for the network. Positive values (red) indicate Adult

933 enrichment and negative values (blue) indicate E16.5 enrichment. $p$ values are corrected for

934 multiple measures using Bonferroni correction. $* * p \leq 0.01, * * * p \leq 0.001, * * * * p \leq 0.0001$. (E)

935 Schematics demonstrating the interaction of $\mathrm{NKCC} 1, \mathrm{Na}^{+} / \mathrm{K}^{+}$-ATPase, and Klotho on the apical

936 membrane of a ChP epithelial cell (CPEC). (F-G) RT-qPCR and immunoblotting of LVChP

937 during postnatal development. (H) Fluorescence images of Calcein-AM labeled epithelial cells

938 from LVChP explants under high extracellular $\mathrm{K}^{+}$challenge. Scale bar $=50 \mu \mathrm{m}$. (I-J)

939 Quantification of ChP epithelia cellular volume by IMARIS 3D analysis. Percent volume

940 increase $=\mathrm{dV} / \mathrm{V}_{0}$ for each timepoint $(\mathrm{t}) . \mathrm{V}_{0}=$ initial volume of the cell; $\mathrm{t}=$ subsequent timepoint

941 after addition of challenge; $d V=V_{t}-V_{0} \times 100 \%$. At least 10 cells were analyzed for each explant

942 from one animal; $\mathrm{N}=4$. 
$\mathrm{Xu}$ and Fame, et al. 42

Figure 3
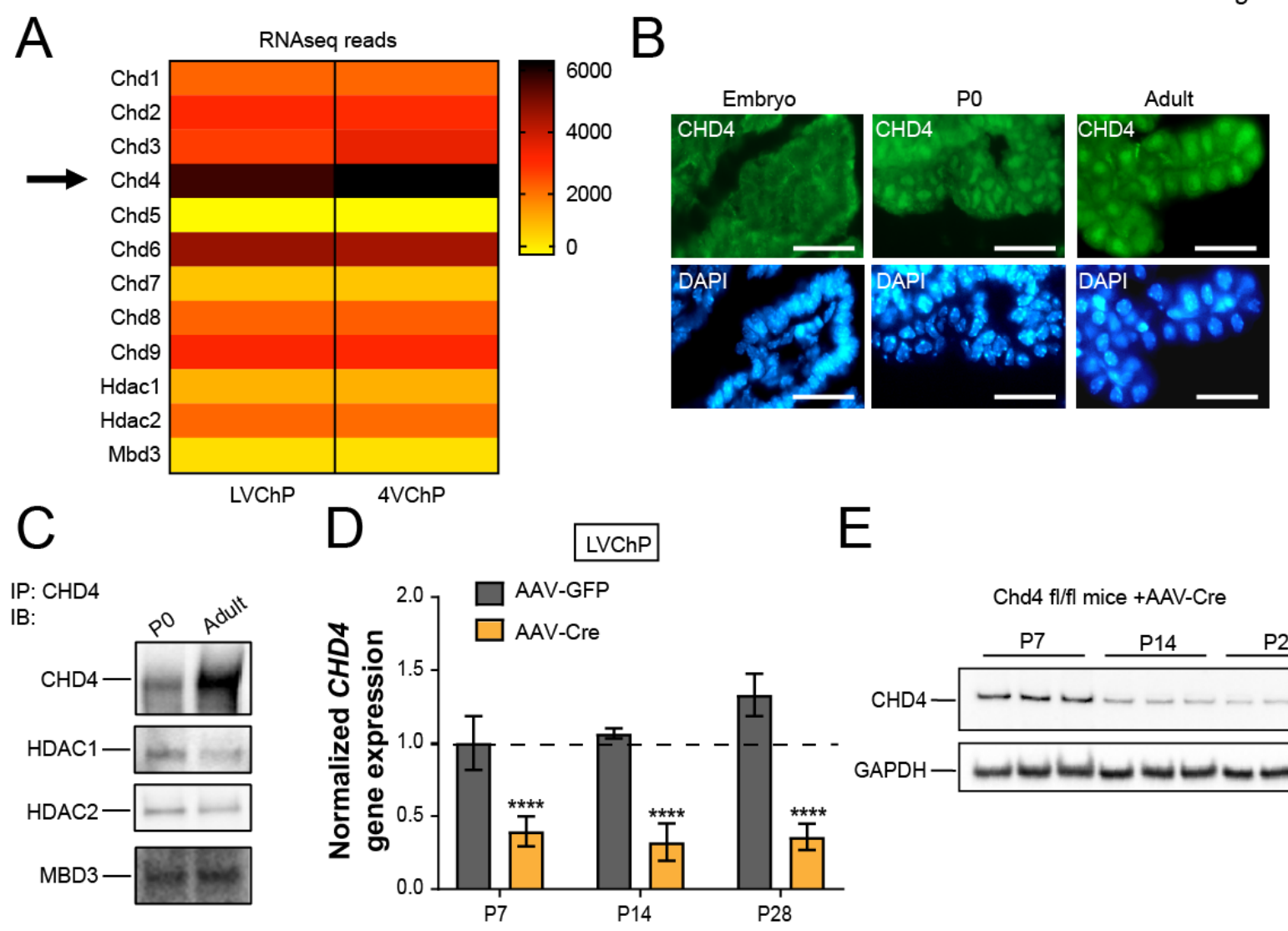

$\mathrm{F}$

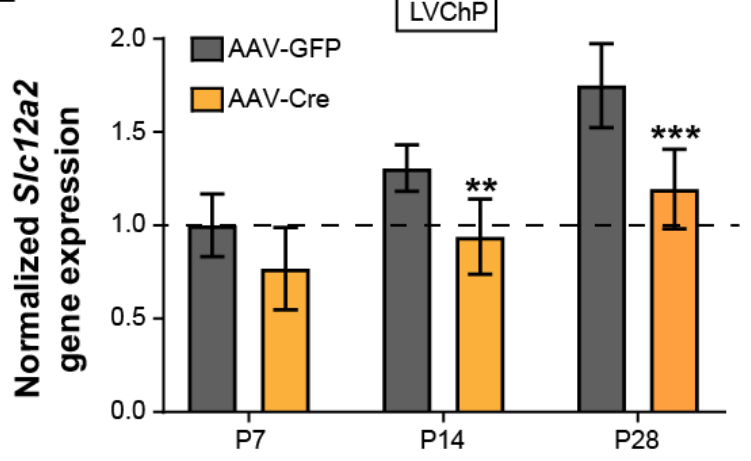

$\mathrm{H}$

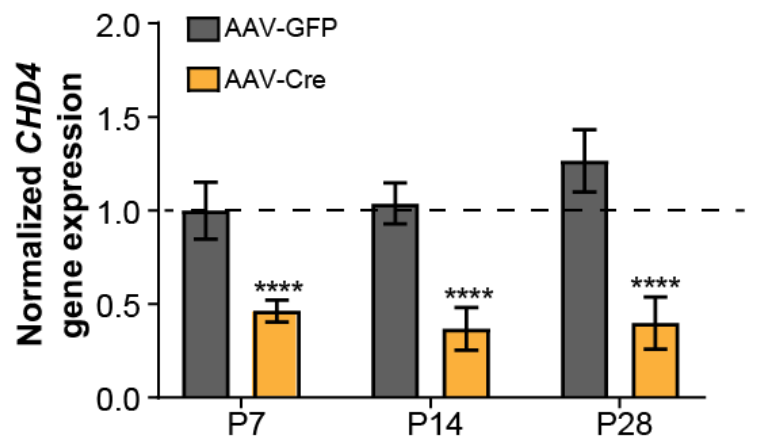

G Chd4 fl/fl mice; LVChP
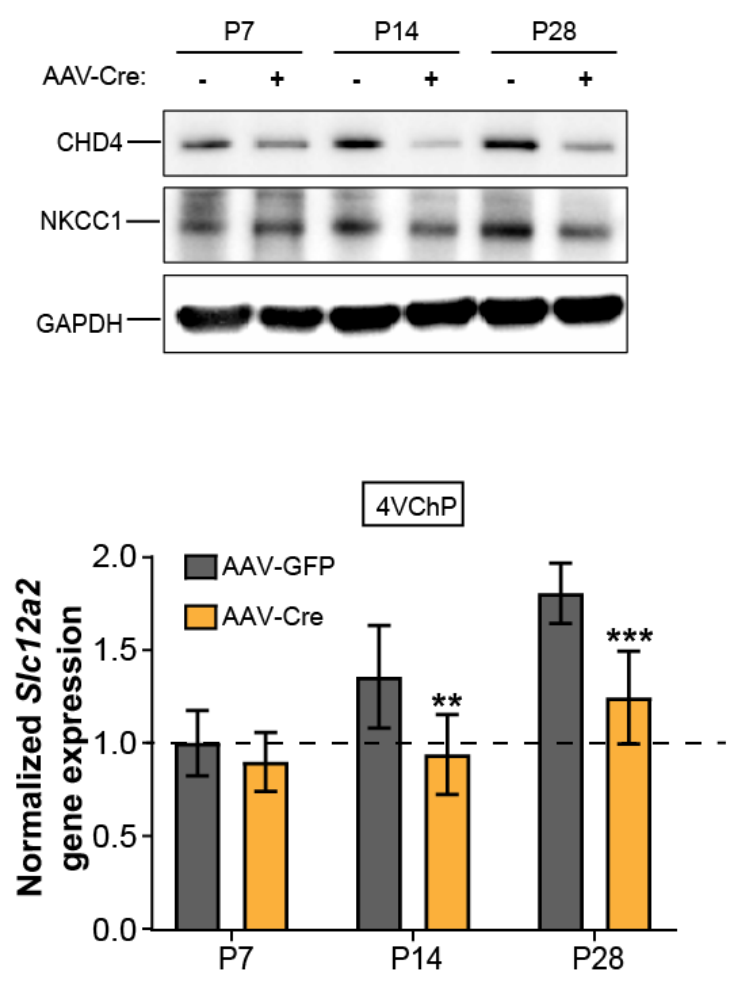
944 Fig. 3. NKCC1 temporal expression requires CHD4/NuRD complex. (A) RNAseq data

945 showing expression of CHD and other NuRD units by the ChP. (B) Immunofluorescence images

946 of CHD4 in the ChP epithelia at E16.5, P0, and adult; Scale bar $=30 \mu \mathrm{m}$. (C) Immunoblots of

947 Co-IP by CHD4 antibody. (D) RT-qPCR of CHD4 transcripts in ChP with AAV2/5-Cre

948 infection. ${ }^{* * *} p<0.0001, \mathrm{~N}=7$, Welch's t-test. (E) Immunoblot of CHD4 in AAV-cre mice

949 ChP lysate with. (F) RT-qPCR of NKCC1 expression in AAV-cre vs. AAV-GFP mice ChP. All

950 values were normalized to P7 AAV-GFP control mice. $* * p=0.0015, * * * p<0.001, \mathrm{~N}=7$

951 Welch's t-test. (G) Immunoblot of NKCC1 in LVChP lysates from AAV-cre vs. AAV-GFP mice.

952 (H-I) CHD4 and NKCC1 RT-qPCR in 4VChP. ** $\mathrm{p}=0.0083, * * * p<0.001, * * * * p<0.0001$,

$953 \mathrm{~N}=7$, Welch's t-test. 
$\mathrm{Xu}$ and Fame, et al. 44

Figure 4
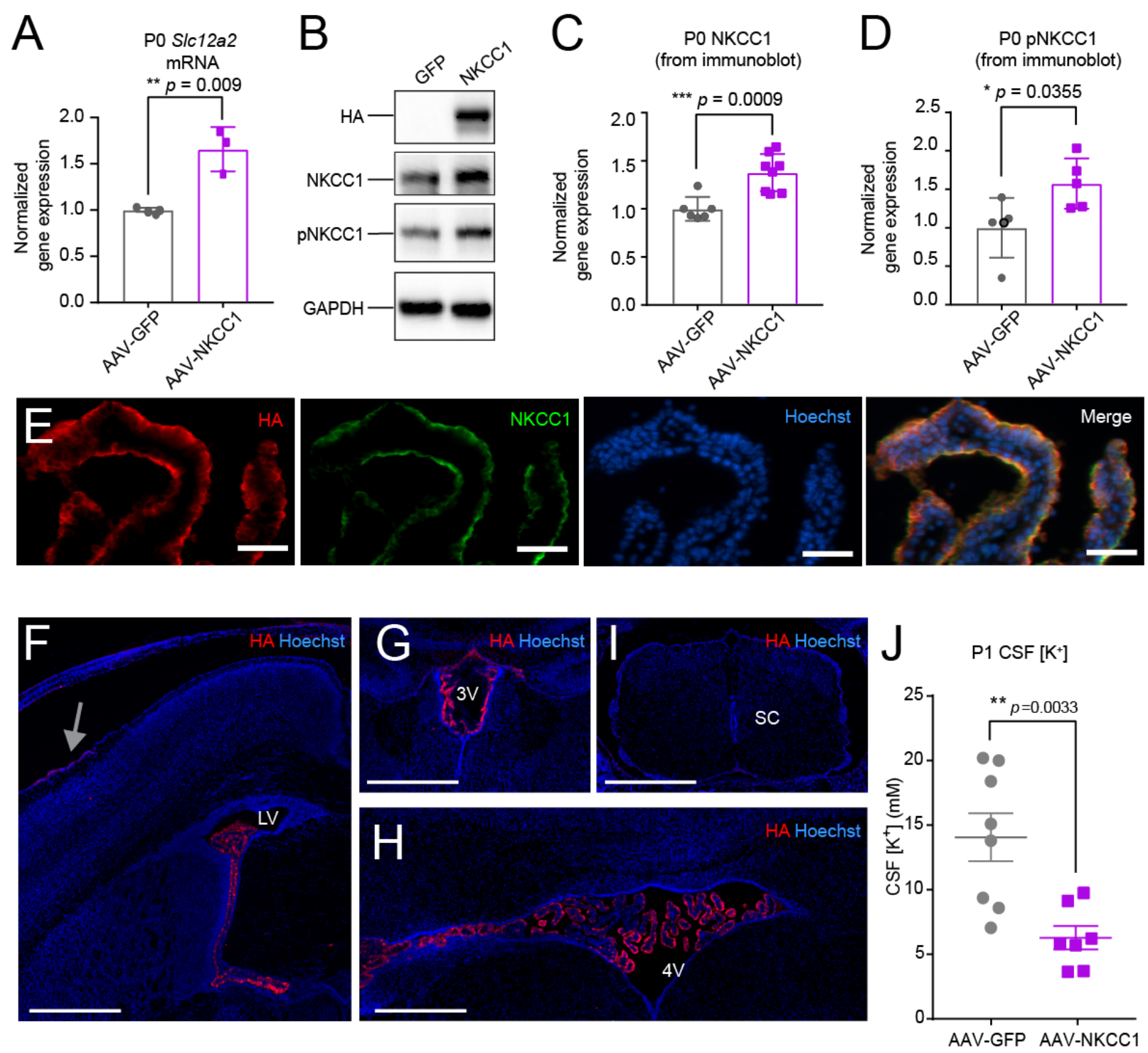
$\mathrm{Xu}$ and Fame, et al. 45

956 Fig. 4. ChP NKCC1 actively mediates CSF $\mathrm{K}^{+}$clearance in the first postnatal week. (A) RT-

957 qPCR of NKCC1 mRNA levels in P0 mice. ** $p=0.009, \mathrm{~N}=3$; Welch's t-test. (B) Immunoblots

958 from AAV-NKCC1 vs. AAV-GFP P0 mice ChP lysates. (C-D) Quantification of all

959 immunoblots of $\mathrm{NKCC} 1(\mathbf{C}) * * * p=0.0009, \mathrm{~N}=7$; Welch's t-test; and pNKCC1 (D) * $p=$

$960 \quad 0.0355, \mathrm{~N}=5$; Welch's t-test. (E) Immunofluorescence images showing co-localization of 3xHA

961 tag and NKCC1 in P0 ChP. Scale bar $=50 \mu \mathrm{m}$. (F-I) Immunofluorescence images of HA in

962 AAV2/5-NKCC1 transduced brain at P1: the LVChP $(\mathbf{F}), 3^{\text {rd }}$ ventricle ChP $(3 \mathrm{VChP} ; \mathbf{G}), 4 \mathrm{VChP}$

963 (H), and the spinal cord $(\mathbf{I} ; \mathbf{s c}=$ spinal cord $)$. Traces of HA is shown in the meninges near the

964 injection site (grey arrow). Scale bar $=500 \mu \mathrm{m}$. (J) ICP-OES measurements of CSF $\left[\mathrm{K}^{+}\right]$from

965 AAV-NKCC1 vs. AAV-GFP P1 mice $(\mathrm{N}=8$ in AAV-GFP cohort; $\mathrm{N}=7$ in AAV-NKCC1

966 cohort). ${ }^{* *} p=0.0033$; Welch' t-test.

967

968

969 
$\mathrm{Xu}$ and Fame, et al. 46
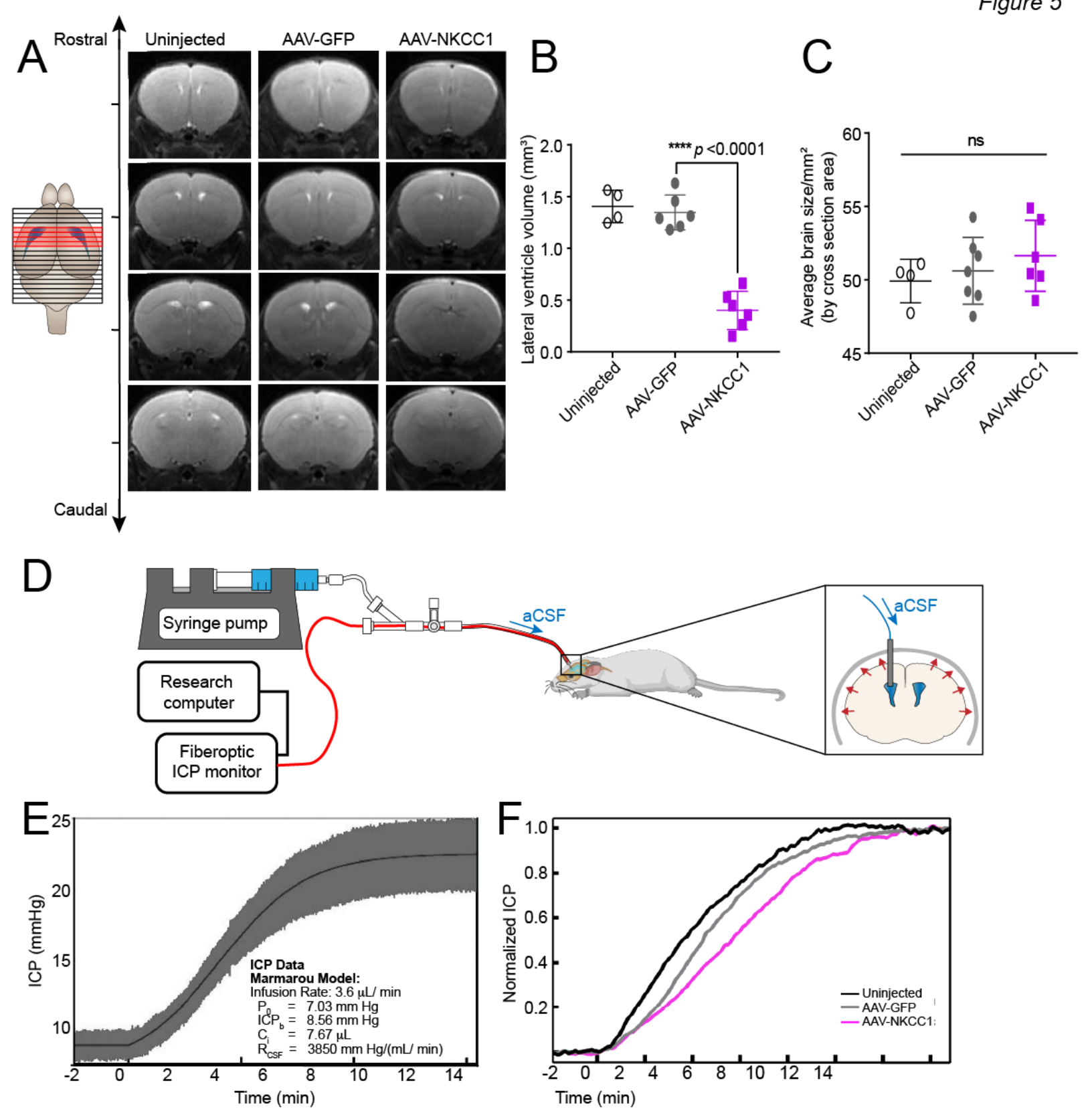

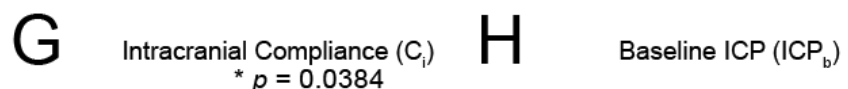
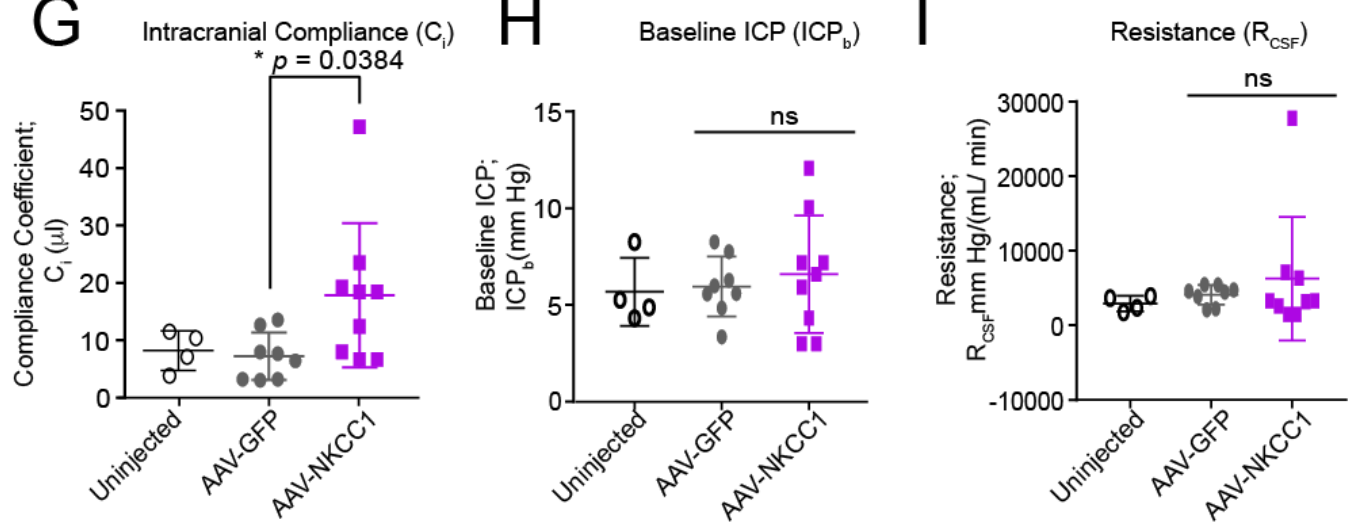


\section{Fig. 5. ChP NKCC1 overexpression reduces brain ventricular volume and increases}

972 intracranial compliance. (A) T2-weighted live MRI images. Only slices with visible LV are

973 shown (marked red in the schematics). (B) LV volumes. Uninjected N = 4; AAV-GFP and AAV-

974 NKCC1 $\mathrm{N}=6$; $* * * * p<0.0001$; Welch's t-test. (C) Brain sizes, which are presented as the

975 average coronal section area from all images with visible ventricles (NKCC1 OE data were

976 calculated using the matching images to the controls, regardless of ventricles visibility).

977 Uninjected $\mathrm{N}=4$; AAV-GFP and AAV-NKCC1 N = 6; Welch's t-test. (D) Schematic of in vivo

978 constant rate CSF infusion test. (E) Example of ICP curve during the infusion test (infusion

979 begins at $0 \mathrm{~min}$ ) in an AAV-GFP mouse, fitted to Marmarou's model. Values extracted include:

980 baseline ICP $\left(I C P_{b}\right)$, a pressure-independent compliance coefficient $\left(C_{i}\right)$ and the resistance to

981 CSF outflow $\left(R_{C S F}\right)$. (F) Example ICP recordings from AAV-NKCC1 mice and controls. For

982 clarity, data have been low pass filtered to remove the waveform components. (G) Compliance

983 coefficients. Uninjected $\mathrm{N}=4$; AAV-GFP N =8; AAV-NKCC1 N =9; ${ }^{*} p=0.0384$; Welch's t-

984 test. (H-I) Plots of baseline ICP and resistance to CSF outflow $\left(\mathrm{R}_{\mathrm{CSF}}\right)$ at 5-7 weeks. Uninjected

$985 \mathrm{~N}=4$, AAV-GFP N=8, AAV-NKCC1 N=9; Welch's t-test. 
$\mathrm{Xu}$ and Fame, et al. 48

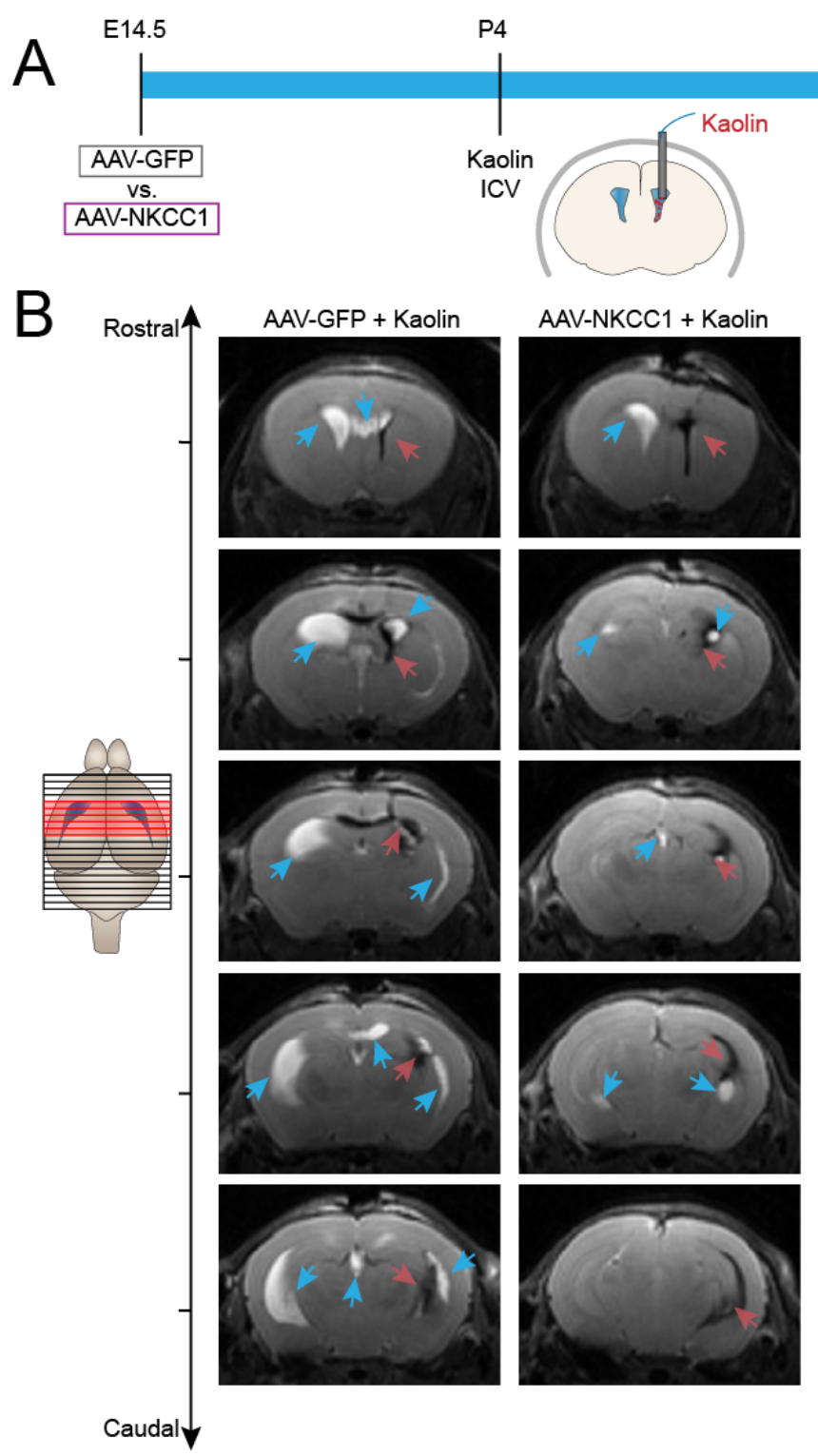

Figure 6

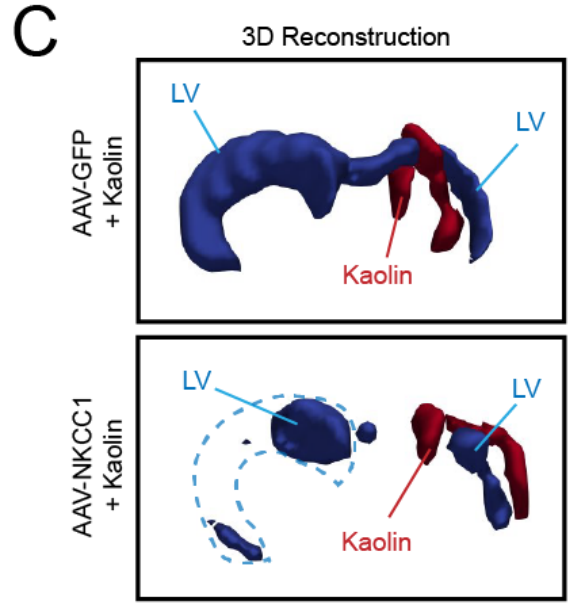

D

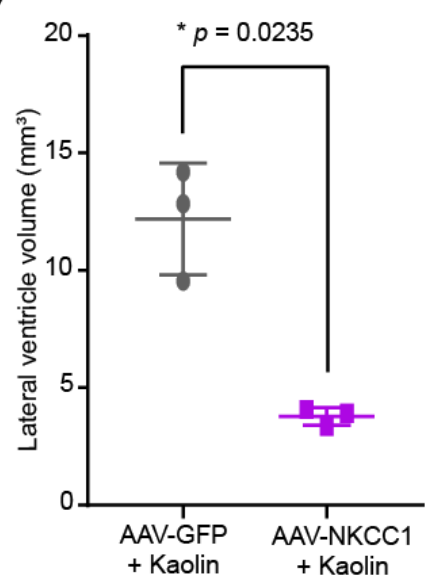


Xu and Fame, et al. 49

988 Fig. 6. ChP NKCC1 overexpression mitigates ventriculomegaly in an obstructive

989 hydrocephalus model. (A) Schematics showing the workflow: E14.5 in utero ICV of AAV2/5-

990 NKCC1 or AAV2/5-GFP, followed by ICV of kaolin at P4, and MRI at P14. (B) Representative

991 sequential brain images (rostral to caudal) by T2-weighted live MRI images. Blue arrows: LV.

992 Red arrows: kaolin. (C) 3D reconstruction of the LV and kaolin deposition. LV: blue. Kaolin:

993 red. (D) LV volumes. $\mathrm{N}=3 ; * p=0.0 .0235$; Welch's t-test. 
$\mathrm{Xu}$ and Fame, et al. 50

Figure 7
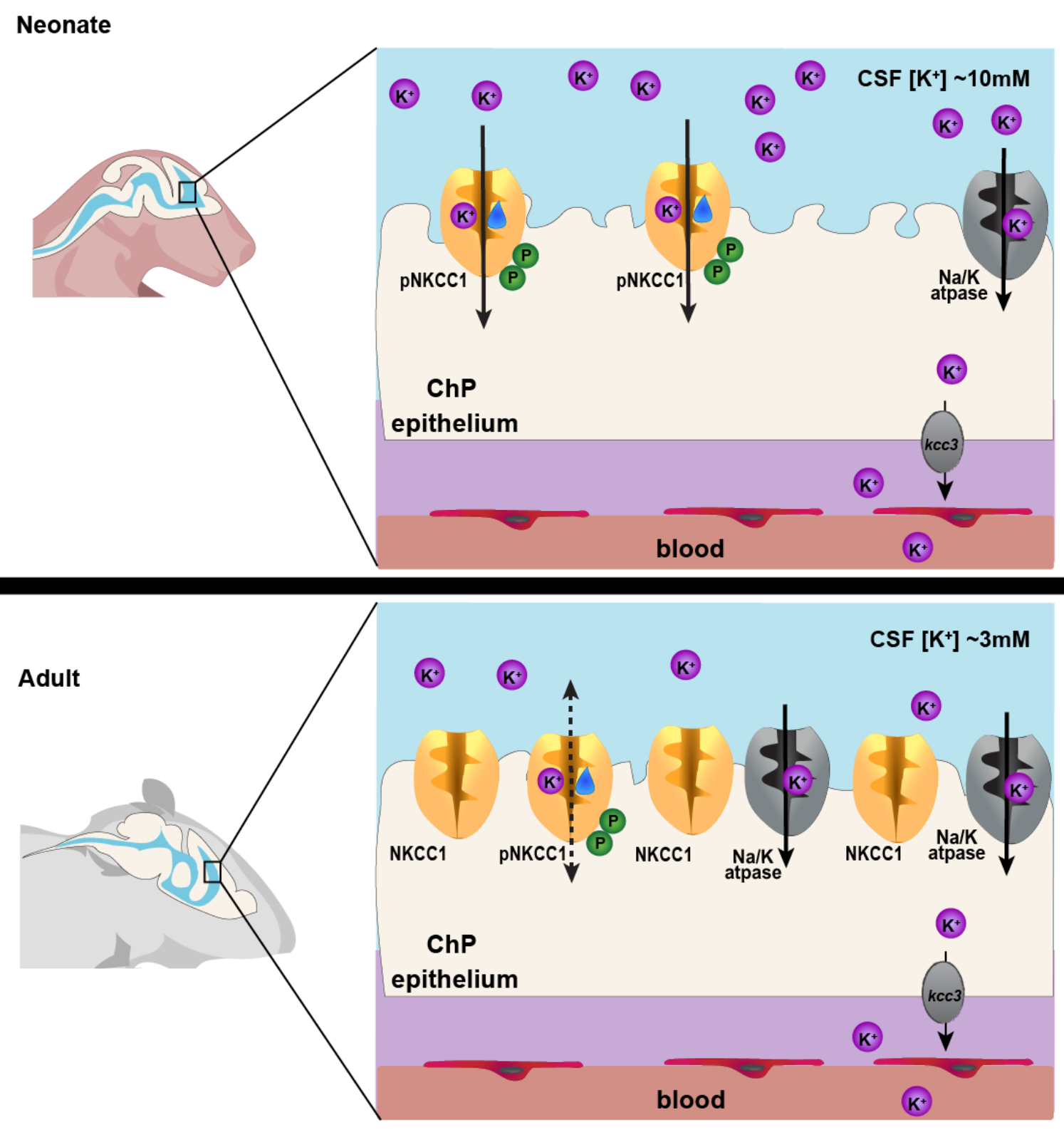
$\mathrm{Xu}$ and Fame, et al. 51

995 Fig. 7. Working model of ChP NKCC1 mediating $\mathbf{K}^{+}$-driven CSF outflow. The schematics

996 describes ChP NKCC1 mediated $\mathrm{K}^{+}$and water clearance from CSF in neonatal mice, in

997 comparison to the adult scenario. For simplicity and clarity, only $\mathrm{K}^{+}$is depicted among all ions

998 and only NKCC1 and $\mathrm{Na}^{+} / \mathrm{K}^{+}$-ATPase are included. Neonatal (P0-7, left) ChP has high pNKCC1

999 than adult, albeit lower total NKCC1. Neonate CSF $\left[\mathrm{K}^{+}\right]$is $2-3$ fold higher than adult. With

1000 similar $\left[\mathrm{Na}^{+}\right]$and $\left[\mathrm{Cl}^{-}\right]$, this $\left[\mathrm{K}^{+}\right]$difference is sufficient to alter the total Nernst potential of

1001 epithelial cells and bias $\mathrm{NKCC} 1$ transport of $\mathrm{K}^{+}$, together with water, out of CSF into the ChP in

1002 neonates.

1003 